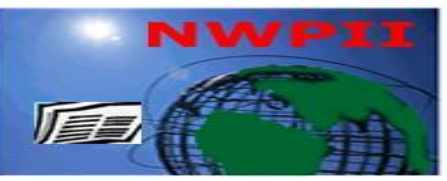

American Journal of Biomedical Sciences

ISSN: 1937-9080

nwpii.com/ajbms

\title{
Advanced Two-State Compressing Algorithm: A Versatile, Reliable and Low-Cost Computational Method for ECG Wireless Applications
}

\author{
Duong Trong Luong*, Nguyen Minh Duc, Nguyen Tuan Linh, Nguyen Thai Ha, \\ Nguyen Duc Thuan
}

Department of Electronic Technology and Biomedical Engineering, Hanoi University of Science and Technology, Vietnam.

*Corresponding Author

Duong Trong Luong

Department of Electronic Technology and Biomedical Engineering

Hanoi University of Science and Technology

Vietnam

Email: luong.duongtrong@hust.edu.vn

Received: 27 December 2015; | Revised: 7 January 2016; | Accepted: 12 January 2016

\begin{abstract}
Compressing the ECG signal is considered a feasible solution for supporting a system to manipulate the package size, a major factor leading to congestion in an ECG wireless network. Hence, this paper proposes a compression algorithm, called the advanced two-state algorithm, which achieves three necessary characteristics: a) flexibility towards all ECG signal conditions, b) the ability to adapt to each requirement of the package size and c) be simple enough. In this algorithm, the ECG pattern is divided into two categories: "complex" durations such as QRS complexes, are labeled as low-state durations, and "plain" durations such $\mathrm{P}$ or $\mathrm{T}$ waves, are labeled as high-state durations. Each duration type can be compressed at different compression ratios, and Piecewise Cubic Spline can be used for reconstructing the signal. For evaluation, the algorithm was applied to 48 records of the MIT-BIH arrhythmia database (clear PQRST complexes) and 9 records of the CU ventricular tachyarrhythmia database (unclear PQRST complexes). Parameters including Compression Ratio (CR), Percentage Root mean square Difference (PRD), Percentage Root mean square Difference, Normalized (PRDN), root mean square (RMS), Signal-to-noise Ratio (SNR) and a new proposed index called Peak Maximum Absolute Error (PMAE) were used to comprehensively evaluate the performance of the algorithm. Eventually, the results obtained were positive with low PRD, PRDN and PMAE at different compression ratios compared to many other loss-type compressing methods, proving the high efficiency of the proposed algorithm. All in all, with its extremely low-cost computation, versatility and good-quality reconstruction, this algorithm could be applied to a number of wireless applications to control package size and overcome congested situations.
\end{abstract}

Keywords: ECG compression, Telemedicine, ECG pattern classification, adaptive package size 


\section{Introduction}

ECG telemedicine is being developed rapidly and is widely used for a variety of medical purposes, such as improving access to medical services, monitoring patients with chronic and cardiovascular diseases or in ambulatory applications [1,2]. Nevertheless, to guarantee the quality of the transmitted ECG signal, a medical network often faces congestion problems that lead to high Bit Error Rate (BER) and high package loss rate, where the size of the transmitted data is a major contributing factor [35]. In low bit rate wireless environments, such as GPRS or HSCSD, different package lengths could cause significant changes in transport delay and jitter, possibly leading to package errors [3]. A larger package size will also increase the number of retransmissions that, as a consequence, will increase the package loss rate due to a higher possibility of packages being discarded [4]. However, continuously reducing the package size does not always produce better performance, since transmission intervals reduce proportionally, and the channels will be extremely busy at a certain level [5]. Therefore, optimizing package size for ECG devices could be an effective solution to maintain performance and utilize channels in a medical wireless network. The sampling rate for digitalizing ECG is always selected to be at least 250 samples/second for portable applications, and up to 1000 samples/second for fully functional monitoring systems in hospitals. Hence, it is difficult to ensure that quality is maintained and there is sufficient channel bandwidth to transmit all the raw data with such large package sizes from different systems. In such a scenario, compressing the ECG signal would be beneficial for transmitting smaller packages without proportionally reducing the interval of transmission. In order to adapt to various applications and clinical situations, the compression algorithm must have three characteristics:

1) It must be flexible for applying to the different shapes of ECG signals without depending on detecting any physiological features, such as $\mathrm{P}$ and $\mathrm{T}$ wave, QRS complex or R peak.

2) Immediately satisfy every adjustment of the package size to guarantee low delay in critical situations.

3) Have a low computational cost at both compression and decompression stages to allow the system to undertake further processing.

A detailed classification of previous works can be found in the Introduction part of Ref. [6]. There are more than 50 compression methods that could be divided into two major sections: 1-D methods and 2-D methods. In 1-D methods, there are also four sub-groups including direct-time domain compression methods (DTD), model based compression methods (MB), transform domain compression methods (TD) and hybrid compression methods $(\mathrm{H})$. Except for DTD methods[7-10], which can achieve all three characteristics mentioned above, the other groups have their own disadvantages preventing their widespread use in different applications. MB methods need to detect QRS complexes or $\mathrm{R}$ peaks to capture different shapes of beats for storage in their codebooks [11-14], or for learning mechanism and compression in case of using Vector Quantization technique (VQ) [1518].TD methods [6], [19-39] which use different transformations such as Wavelet transform, discrete cosine transform, etc., hardly satisfy the change of compressed data size without affecting the quality of reconstruction, since they depend on the size of processing block. Besides that, although the reconstruction were extremely good at very high compression ratio due to various modifications in transformation techniques or error minimization mechanisms, the considerable computational cost causes TD methods to be hardly applied in a network with multiple ECG devices. Likewise, H[40-42] and 2-D methods [43-48] are even more computationally complex and are difficult for implementing in wireless applications as a step. DTD methods, such as turning point (TP) [7], amplitude zone time epoch coding (AZTEC) [8], the coordinate reduction time encoding (CORTES) [9] and scan along polygonal approximation (SAPA) [10], are the most flexible ones compared to others, since 
they are simple enough and independent of ECG features (these algorithms actually only detect slopes in general, not $\mathrm{P}$ and $\mathrm{T}$ waves or QRS complex). Nevertheless, almost all of them except SAPA cannot re-produce a reliable ECG signal. A comprehensive review about these algorithms was done in Ref. [49]. Therefore, this paper aims to add a novel, extremely simple, versatile and enough reliable compression algorithm to the DTD group, called the advanced two-state algorithm, using two different compression ratios to compress two types of durations in the ECG signal: complex durations and plain durations, and apply Piecewise Cubic Spline, a basic interpolation algorithm, for decompressing the signal. Details of the proposed method are given in section 2. In section 3, we survey the performance of the algorithm with two types of ECG signals: signals with clear PQRST complexes (BIH-MIT arrhythmia database [50]) and signals with unclear PQRST complexes (CU ventricular tachyarrhythmia [51]). We discuss our results in section 4 and, our conclusions are provided in the last section.

\section{Two-state compressing algorithm}

\subsection{Principle and overview of the two-state compressing algorithm}

Many compressing methods share the same idea of separating QRS complexes containing high frequency components, from $\mathrm{P}$ and $\mathrm{T}$ waves, which only consist of low frequency components. However, almost algorithms used in those methods tend to detect exactly $\mathrm{R}$ peaks or $\mathrm{QRS}$ complexes that can reduce their versatility and flexibility in case of irregular ECG signals as well as increase the cost of computation. To overcome this problem, the proposed algorithm tends to distinguish between complex durations in general, in which QRS complexes are particular examples, and plain durations in general, which include $\mathrm{P}$ and $\mathrm{T}$ waves, by a simpler method of using two thresholds in the first derivative of the signal (Figure 1). The first derivative of the ECG signal is calculated as below:

$$
\begin{gathered}
\mathrm{y}_{\mathrm{i}}^{\prime}=\frac{\mathrm{y}_{\mathrm{i}+1}-\mathrm{y}_{\mathrm{i}}}{\Delta \mathrm{x}}=\mathrm{y}_{\mathrm{i}+1}-\mathrm{y}_{\mathrm{i}} \\
\text { with } \Delta \mathrm{x}=1 \text { and } \mathrm{i}=0,1 \ldots, \mathrm{n}-1
\end{gathered}
$$

Where, $\mathrm{n}$ is the number of ECG samples, $\mathrm{y}_{\mathrm{i}}$ and $y_{i}^{\prime}$ are the $i^{\text {th }}$ ECG's sample and the $i^{\text {th }}$ first derivative sample. As clearly seen, $y_{i}^{\prime}$ is in fact the difference between $y_{i}$ and its previous sample,thus it can help distinguish the pattern as a low- or high-frequency duration. Considering a short period of record number 103 of MIT-BIH arrhythmia (Figure 1), which has clear PQRST shapes, the $\mathrm{P}$ and $\mathrm{T}$ waves exhibit a moderately flat pattern in the first derivative, expressing their slow changing curves, which could be classified easily by a threshold $\boldsymbol{T h r} \mathbf{l}$. If a sample is equal to or larger than Thr1, it would indicate a possible upcoming complex duration like QRS complexes. To capture sufficient complex durations in the first derivative, a smaller threshold $\mathbf{T h r} \mathbf{2}$ is used. By continuously finding samples smaller than Thr2, the end of QRS will be defined, and the threshold is switched back to Thr1.As a result, plain durations and complex durations could be eventually separated by this extremely low-cost computational mechanism. After classification, both complex durations and plain durations are compressed simply by a downsampling process, which decreases the sampling frequency of the signal by just removing the samples:

$$
\tilde{y}_{i}=y_{i * k} \text { withi }=0,1 \ldots, \mathrm{m}-1
$$

Wherein, $\mathrm{h}, \tilde{y}_{i}$ is the $\mathrm{i}^{\text {th }}$ sample of the compressed signal, $\mathrm{m}$ is the number of samples after compressing, $\mathrm{k}$ is the downsample factor $(D F)$ and in this case, it is also the compression ratio $(C R)$ of that duration. Henceforth, we will use the term CR instead of DF throughout the manuscript to be more precise in terms of the compressing data. The classification mechanism and the downsampling process above form the principle of the proposed two-state algorithm: the ECG pattern will be divided into two types: (i) plain durations like $\mathrm{P}$ and $\mathrm{T}$ waves (low frequency components), which could be downsampled at a higher $\mathrm{CR}(\boldsymbol{h} \boldsymbol{C R})$ and are labelled as high-state, and (ii) complex durations like QRS (high frequency components), which 
could be downsampled at a lower CR $(\boldsymbol{I C R})$ and are labelled as low-state. As a result, a more optimized overall compression ratio $(\boldsymbol{o C R})$ could be achieved for the signal. In this algorithm, the values of $\boldsymbol{h} \boldsymbol{C R}$ and $\boldsymbol{I C R}$ have to satisfy:

$\boldsymbol{h C} \boldsymbol{R}=\mathbf{n} * \boldsymbol{l C} \boldsymbol{R}$ with $\mathrm{n}$ being an interger and $\mathrm{n} \geq 1$, which will be further explained in the next section.
To keep consistency while presenting the method and evaluating the results, the terms "plain" and "complex" in this section, which were first propounded by Kim. et.al. [34] will be used along with $\boldsymbol{h C R}, \boldsymbol{l C R}, \boldsymbol{o C R}, \mathrm{Thr} \mathbf{l}$ and $\mathbf{T h r} \mathbf{2}$ terminologies in this paper.

\section{Complex duration}

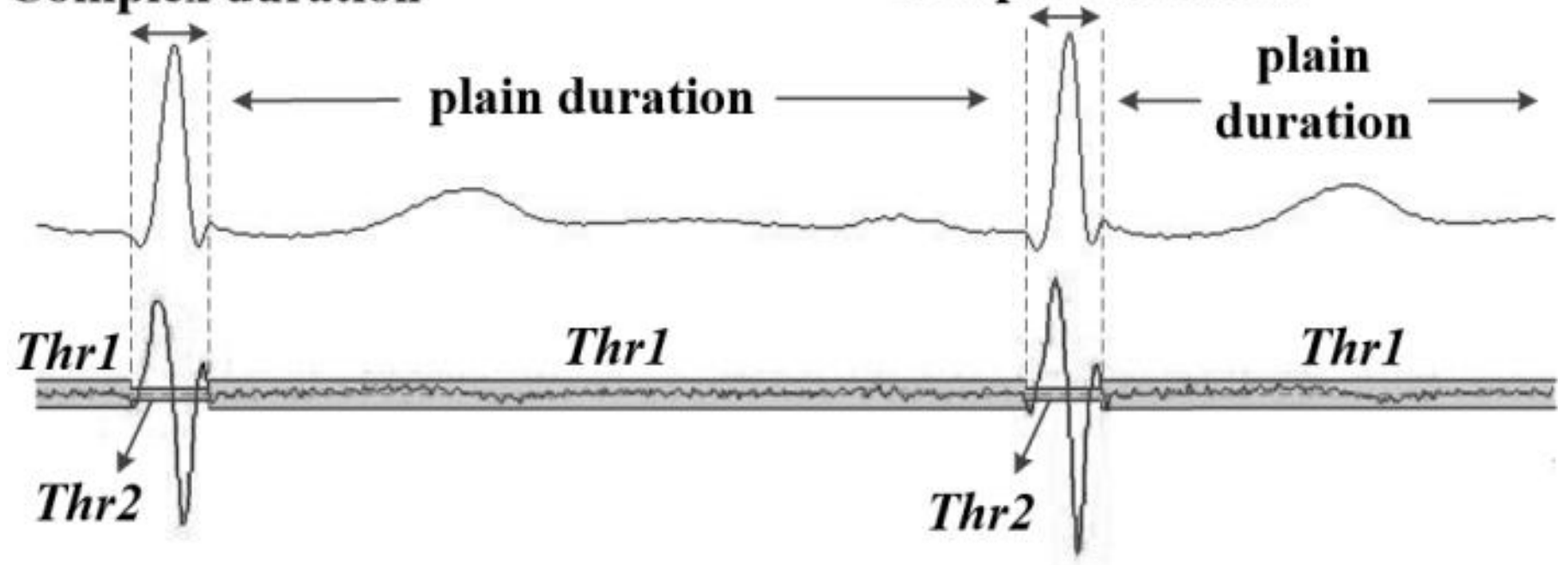

Figure 1. Record 103 of MIT-BIH arrhythmia database (above), its first derivative (below).Tthe complex durations and plain durations are distinguished by two thresholds in the first derivative signal

An overview of the proposed two-state algorithm is presented in Figure 2. There are four major compressing steps and three major decompressing steps. For the compressing steps, a block with the length of $\mathbf{L}=\boldsymbol{h} \boldsymbol{C R}$ samples is continuously scanned throughout the first derivative of the signal (Figure 1). The block is first classified as a low-state or high-state block (procedure 1), then compressed with $\boldsymbol{h} \boldsymbol{C R}$ or $\boldsymbol{l C R}$ based on its state, but storing the backward differences instead of the ECG samples (procedure 2). Next, some special samples, called state-changed-markers, are added to mark a change of state if available(procedure 3). This finally, represents the backward differences to improve the overall CR (procedure 4). At the end of the process, this block will be compressed to only one sample in case of high-state or $\mathrm{n}=$ $\boldsymbol{h C R} / \boldsymbol{l C R}$ samples in case of low-state before moving to the next block. This kind of sampleunit process can help the system to control the size of the package easily and continuously in extremely short time.

For the decompression process, the recipient compressed signals will be reclassified based on the marking samples (procedure 5), followed by inversing the difference to get complete ECG samples (procedure 6) and reconstructed using Cubic Spline (procedure 7). 


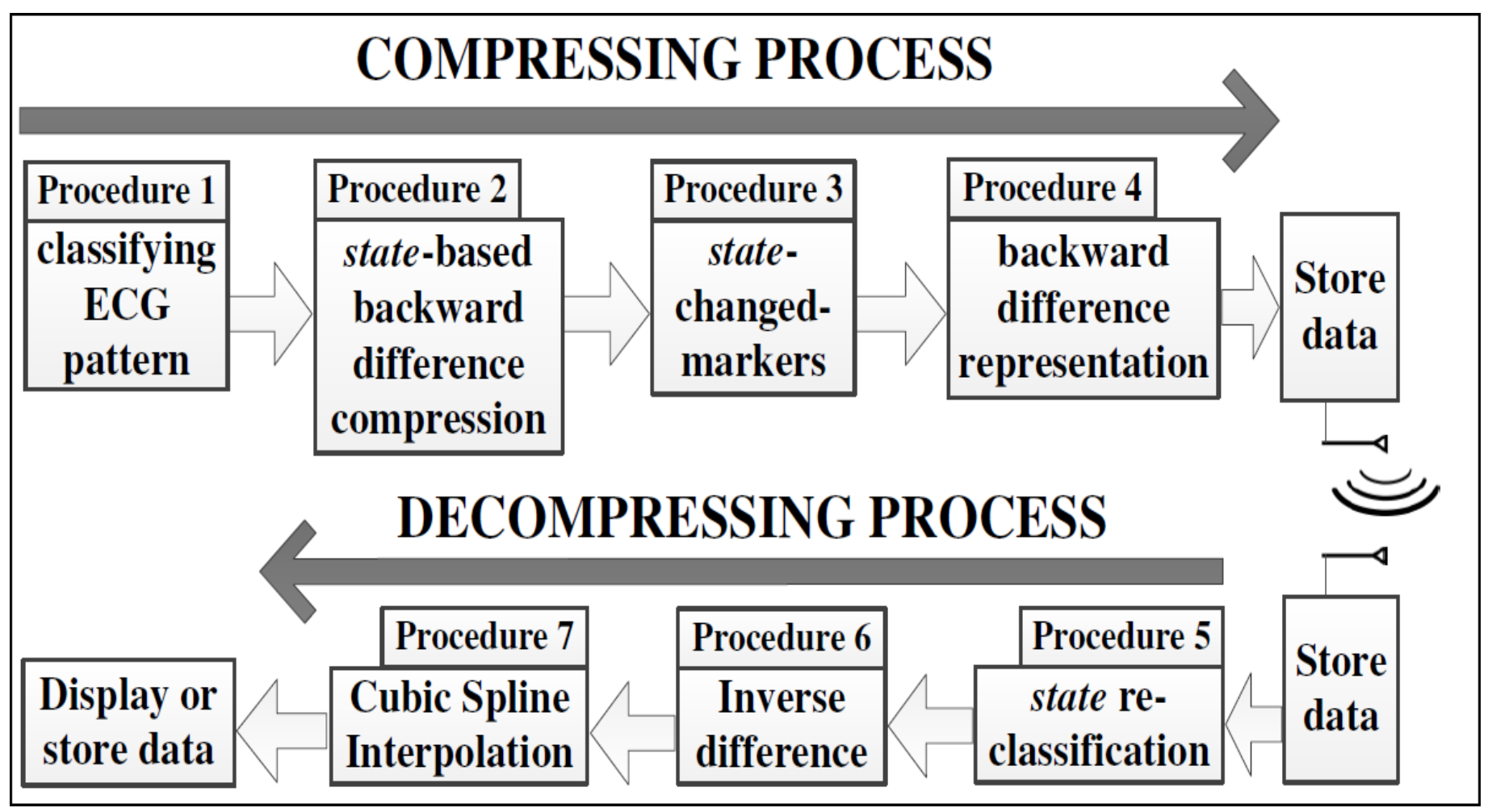

Figure 2. The overview of the advanced two-state algorithm.

2.2 Classification of ECG patterns (stateclassifying).

As mentioned above, a block of $\boldsymbol{L}=$ $\boldsymbol{h} \boldsymbol{C R} \boldsymbol{y}^{\prime}$ samples (the first derivative samples) will be compared to two thresholds Thr1 and Thr2before being labelled as a low-state or a high-state block. There are two main steps involved in this process, which is presented below (Figure 3):

\subsubsection{Process A (high-state classification)}

First, a block of $\boldsymbol{L}$ consecutive y' samples are compared to $\boldsymbol{T h r} \mathbf{l}$. If all these samples satisfy the condition: $y_{i}^{\prime}<\boldsymbol{T h r} \mathbf{1}$, with $\mathrm{i}=0,1, \ldots, \mathrm{L}-1$, then this block is classified as a high-state block since it only contains plain data. In contrast, if at least one component exceeds Thrl, this will be labelled as the first low-state block, marking an end of a plain duration and the program will switch to process B.

\subsubsection{Process B (low-state classification)}

Here, all the subsequent y' samples will be compared to the smaller value $\boldsymbol{T h} \boldsymbol{r} \mathbf{2}$. If a block has at least one sample bigger than $\boldsymbol{T h} \mathbf{2}$, it is still considered to be in low-state duration. In contrast, if all samples within a block are smaller than $\boldsymbol{T h} \boldsymbol{2}$, then the previous block will be the final low-state block and the program is switched back to process A. Moreover, since $\boldsymbol{I C R}$ will be applied for these blocks, $\boldsymbol{l C R}$ must be a divisor of $\boldsymbol{h C R}$ to match the size of the block.

To guarantee a full capture, the low-state duration is extended by one block on each side. The structure of each block and the corresponding conditions are also presented in Figure 4. 


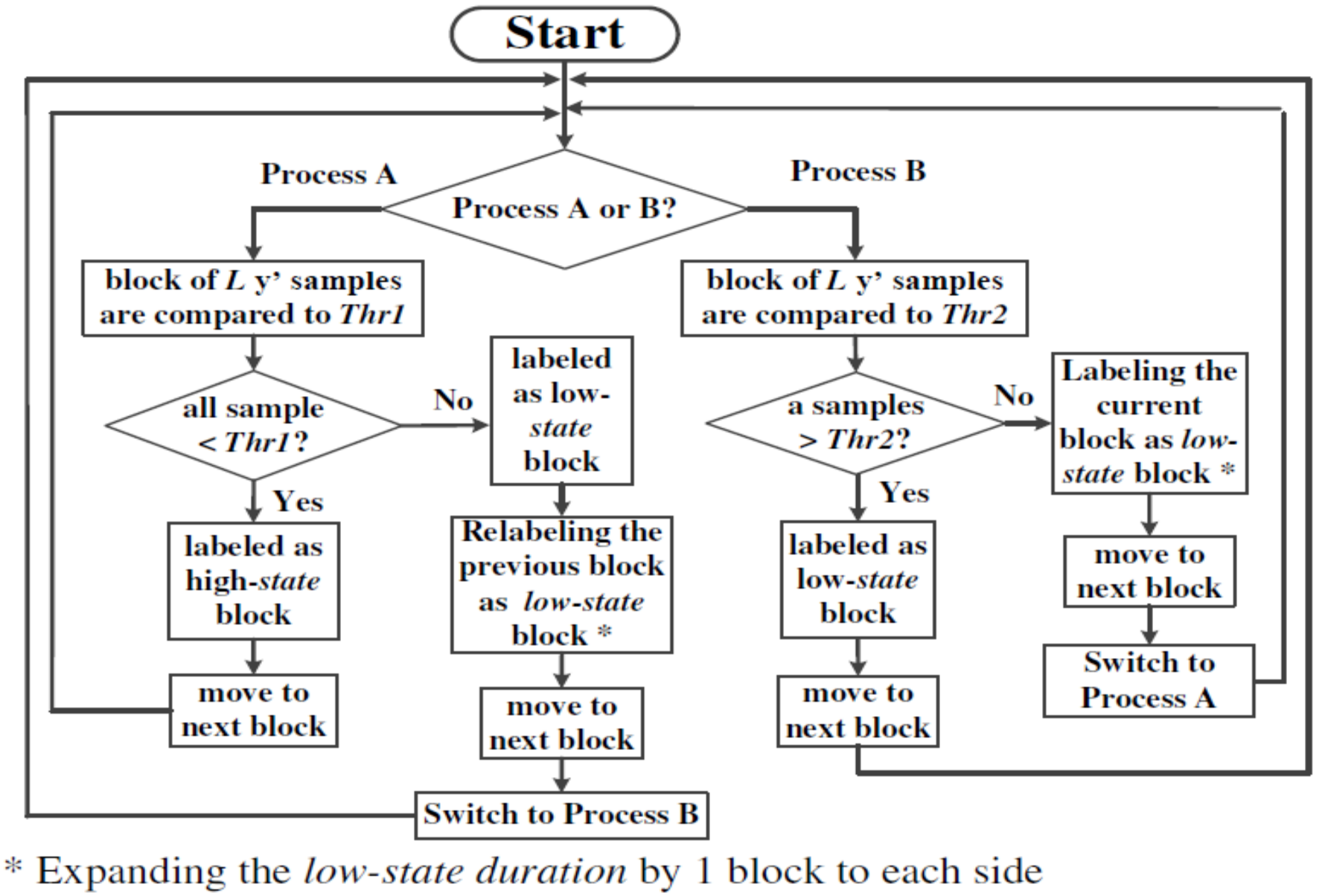

Figure 3. Flowchart of the ECG pattern classification (state classification) procedure presening two processes: Process A for high-state classification (left branch) and Process B for low-state classification (right branch).

\begin{tabular}{|c|c|c|c|c|c|c|c|c|c|c|}
\hline \multicolumn{11}{|c|}{ The ECG's first derivative samples } \\
\hline \multicolumn{4}{|c|}{ high-state duration } & \multicolumn{6}{|c|}{ low-state duration } & $\bullet \bullet \bullet$ \\
\hline $\begin{array}{c}1^{\text {st }} \text { high-state } \\
\text { block }\end{array}$ & $\begin{array}{l}2^{\text {nd }} \text { high- } \\
\text { state block }\end{array}$ & & $\begin{array}{l}\text { final high- } \\
\text { state block }\end{array}$ & $\begin{array}{c}\text { extended } \\
\text { low-state block }\end{array}$ & $\begin{array}{c}1^{\text {st }} \text { low-state } \\
\text { block }\end{array}$ & $\begin{array}{c}2^{\text {nd }} \text { low-state } \\
\text { block }\end{array}$ & & $\begin{array}{l}\text { final low- } \\
\text { state block }\end{array}$ & $\begin{array}{c}\text { extended } \\
\text { low-state block }\end{array}$ & \multirow{2}{*}{$\bullet \bullet \bullet$} \\
\hline $\begin{array}{c}\text { All samples } \\
<T h r l\end{array}$ & $\begin{array}{c}\text { All samples } \\
<\text { Thrl }\end{array}$ & 000 & $\begin{array}{c}\text { All samples } \\
\quad<T h r 1\end{array}$ & $\begin{array}{c}\text { All samples } \\
<\text { Thr } 1\end{array}$ & $\begin{array}{c}\text { At least } \\
\text { 1 sample } \\
>\text { Thrl }\end{array}$ & $\begin{array}{c}\text { At least } \\
\text { 1 sample } \\
>\text { Thr1 }\end{array}$ & 000 & $\begin{array}{c}\text { At least } \\
\text { 1 sample } \\
>\text { Thr2 }\end{array}$ & $\begin{array}{c}\text { All samples } \\
<T h r 2\end{array}$ & \\
\hline
\end{tabular}

Figure 4. The structure of classified blocks within each type of duration. Noting that the low-state durations are expanded to each side by 1 block which is originally a high-state block.

We also tested with all 48 records of MITBIH arrhythmia database to find suitable $\mathbf{T h r} \mathbf{l}$ and $\boldsymbol{T h} \mathbf{2}$, and we found that $\boldsymbol{T h r} \mathbf{1}=\mathbf{1 0}$ and $\mathbf{T h r} \mathbf{2}$ $=0.3 \times$ Thr 1 would be the best conditions to capture enough complex durations. Examples of classifying ECG patterns with $\boldsymbol{L}=\boldsymbol{h} \boldsymbol{C}=8$ in records 102, 107, 119 and 123 are shown in Figure 5. 


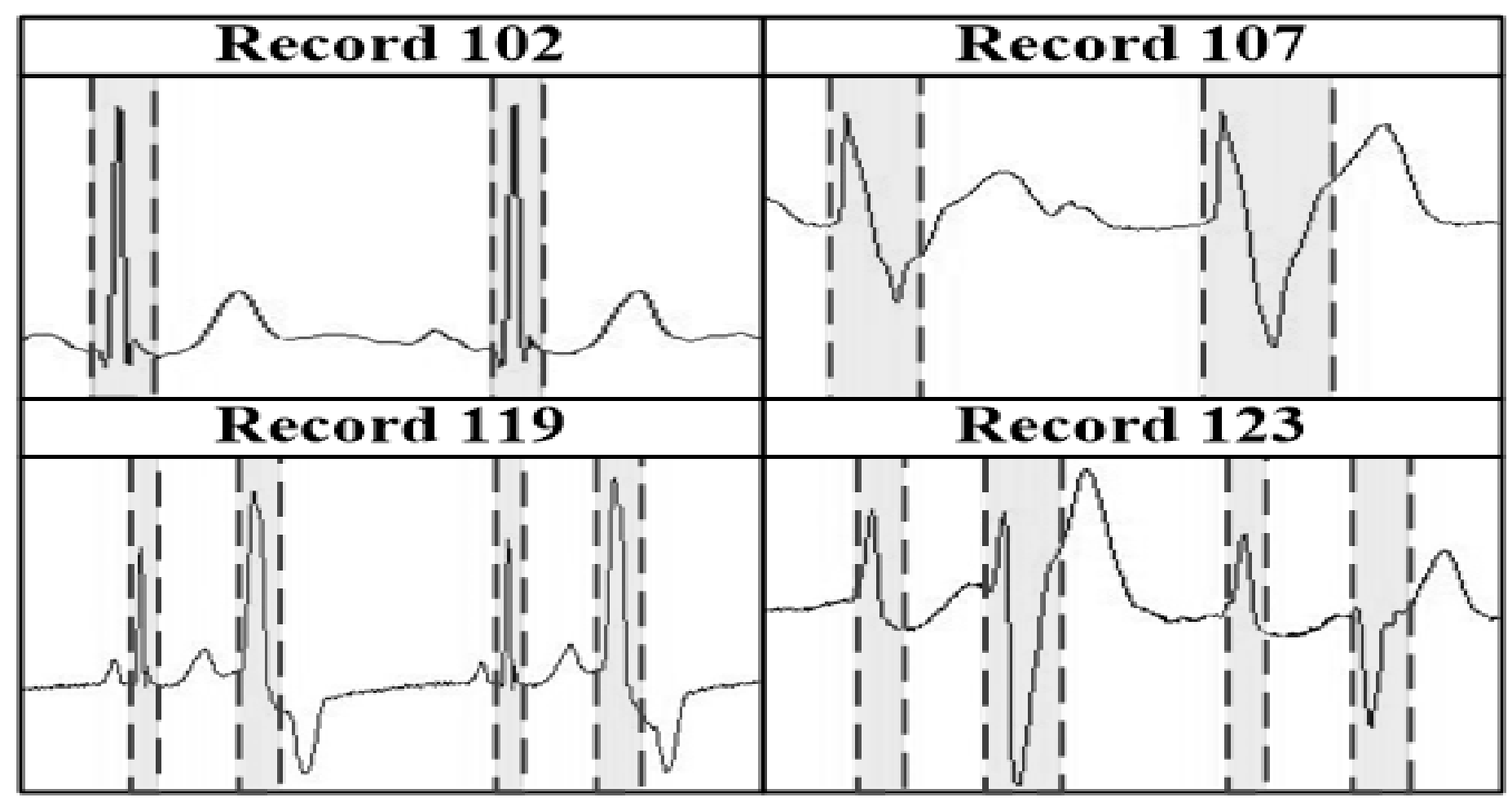

Figure 5. Examples of classifying ECG patterns $(\mathbf{h C R}=8$, Thr1 = 10) in recordings 102, 107, 119 and 123 with grey durations representing the low-state durations.

\subsection{State-based backward difference compression}

After classification, the corresponding block will be compressed depending on its state. If it is a high-state block, only the first sample is stored while the remaining samples within that block will be removed (downsample factor $=\boldsymbol{h C R}$ ). Conversely, in case of a low-state block,this block will be downsampled with a lower downsample factor $=\boldsymbol{l C R}$, or in other words, there will be $\frac{\boldsymbol{h C R}}{\boldsymbol{l C R}}$ samples within a low-state block, which will be saved into the compressed package.In addition, each compressed ECG samples except the first one will be immediately replaced by the difference between itself and its previous sample, called the backward difference: $\Delta \tilde{y}_{i}=\tilde{y}_{i+1}-\tilde{y}_{i}$, with $\tilde{y}_{i+1}$ and $\Delta \tilde{y}_{i}$ is the $(\mathrm{i}+1)^{\text {th }}$ samples of the compressed package and its backwards difference. A full overview of this procedure is shown in Figure 6.

\subsection{State-changed-markers}

This procedure is an important part because it helps the receiver re-classify the pattern of the received package before reconstructing the signal.
Some special samples, called state-changedmarkers, will be added into the intersections between low-state durations and high-state durations. Importantly, this procedure is only enabled when a switch from Process A to Process $\mathrm{B}$ (Procedure 1) or vice versa occurs, and the marking samples have to be unique in order to be recognized clearly. It is worth noting that these marking samples must have the same presentation as the ECG sample, and it is in 2byte form in case of BIH-MIT arrhythmia database and $\mathrm{CU}$ ventricular tachyarrhythmia database.

Specifically, if a high-to-low transition occurs, then an all-bit-1 sample, which has a decimal value of -32768 (signed form) in terms of 2-byte presentations, is added between the final high-state sample and the first low-state sample in the compressed package (Figure 6). In contrast, if a low-to-high happens, two marking samples will be inserted between the final lowstate sample and the first high-state sample, including an all-bit-1 sample and an all-bit-O sample (decimal value of 0) (Figure 6) to mark the end of a low-state duration. 


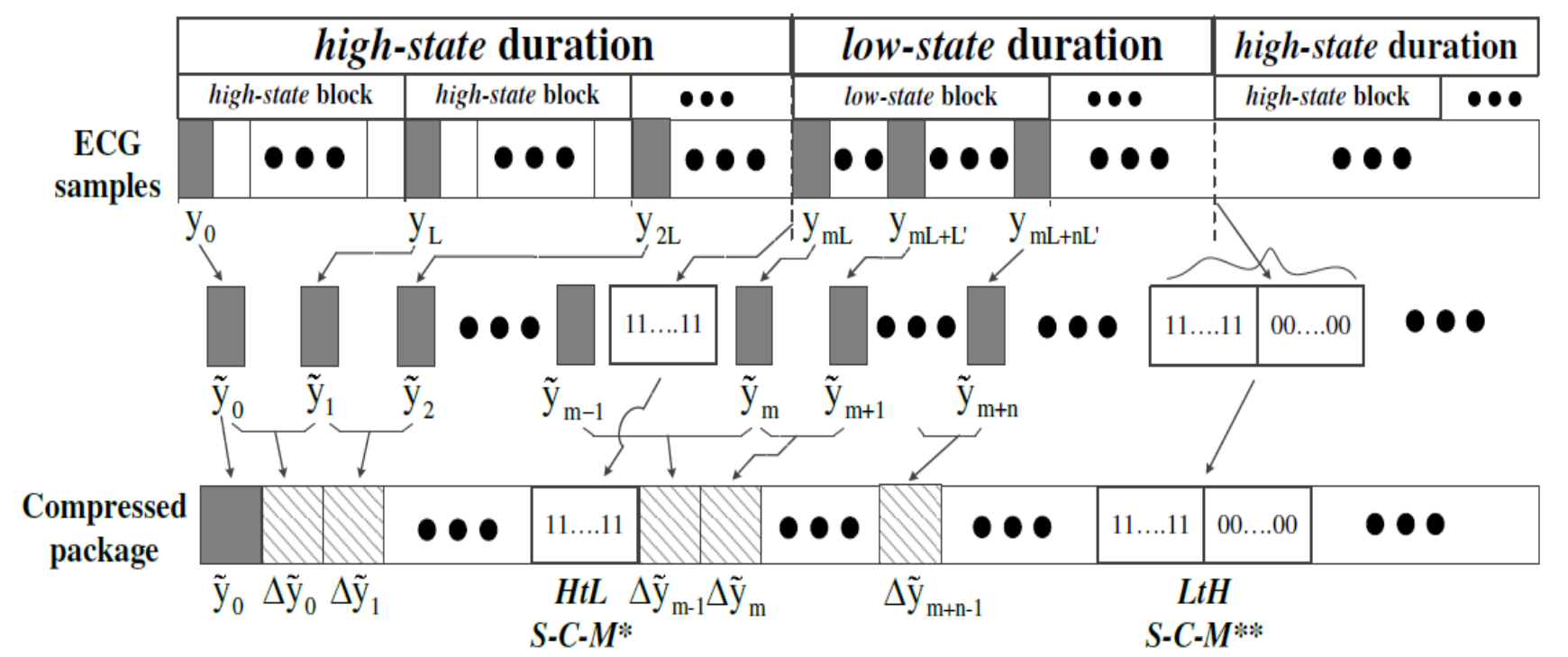

* HtL S-C-M: state-changed-markers indicate a transition from high-state to low-state, which is an all-bit-1 sample (= -32768 for 2-byte form)

** LtH S-C-M: state-changed-markers indicate a transition from low-state to high-state, which includes an all-bit-1 sample (= -32768) and an all-bit-0 sample (=0)

Figure 6. The compressed package structure. In a high-state block, only the first sample is reserved while in a lowstate block, there will be $\mathrm{n}=\mathrm{hCR} / \mathrm{lCR}=\mathrm{L} / \mathrm{L}$ ' samples are kept. Additionally, only the first sample is the ECG sample while the next samples are the backward differences: $\Delta \tilde{y}_{i}=\tilde{y}_{i+1}-\tilde{y}_{i}$, with $\tilde{y}_{i+1}$ and $\Delta \tilde{y}_{i}$ is the $(i+1)^{\text {th }}$ samples of the compressed package and its backwards difference.

\subsection{Backward difference representation}

This procedure will represent the compressed package, which possibly contains samples with 2 byte format, and convert samples into 1-byte format, if possible, to enhance the overall compression ratio (Figure 7). The backward differencesamples are considered subject to satisfying the condition: $-128 \leq y_{i}^{\prime} \leq 127$. Samples that meet the demand could be shortened into 1-byte format without problems, while those that do not meet the criteria will be represented in 2-byte format, in which the first byte is -128 (if $y_{i}^{\prime}<-128$ ) or 127 (if $y_{i}^{\prime}>127$ ), and the second byte stores the difference: $\Delta y^{\prime}=|\Delta \tilde{y}|-128$ (if $\left.y_{i}^{\prime}<-128\right)$ or $\Delta \mathrm{y}^{\prime}=\Delta \tilde{\mathrm{y}}-127$ (if $y_{i}^{\prime}>127$ ). In case of state-changed-markers, all-bit-1 sample will be reserved ( 2 bytes, each byte $=-128)$, while all-bit- $O$ sample will be shortened into 1 byte $(1$ byte $=0)$.

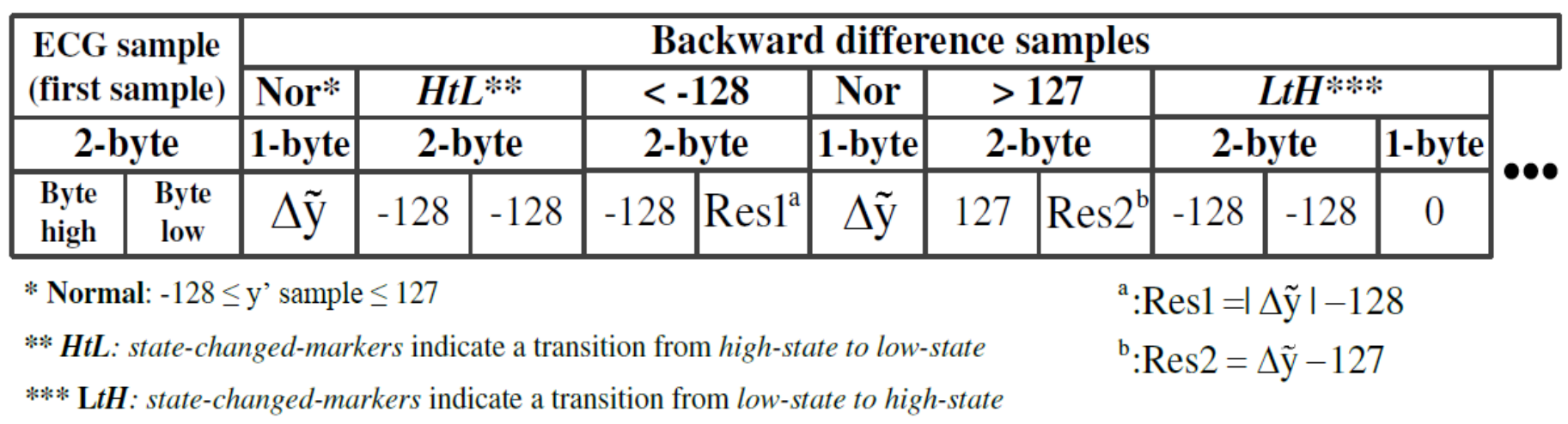

Figure 7. The structure of backward difference representation. 


\subsection{State re-classification}

After receiving a package, the receiver first checks the package to re-detect complex durations and plain durations based on statechanged-markers. The beginning of complex duration will be recognized by detecting two consecutive bytes of -128 , while the end will be marked by two bytes of -128 and one byte of 0 . Due to the fact that state changes alternatively, successfully re-classifying complex durations also lead to successfully re-detecting plain durations. The state-changed-markers are also simultaneously removed in this procedure.

\subsection{Inverse difference}

Before interpolating the compressed signal, the package needs to be reversed to ECG samples instead of samples of differences. Hence, each difference sample will be re-converted into 2byte form and the corresponding ECG sample will be calculated based on the previous ECG sample and the difference, starting from the first ECG sample.

\subsection{Cubic Spline Interpolation}

Finally, the signal will be reconstructed using Cubic Spline noting that different durations will have different distances between samples.

\section{Experiments and results}

\subsection{Indexes for evaluating compression algorithm}

The performance of the proposed algorithm was evaluated by some common indexes presented below, which were also used by many other studies:

1) The compression ratio $(C R)$ :

$$
C R=\frac{N_{\text {origin }}}{N_{\text {comp }}}
$$

$\mathrm{N}_{\text {origin }}$ is the original size and $\mathrm{N}_{\text {comp }}$ is the size of the compressed signal. The $\mathrm{CR}$ calculated here is the overall CR (oCR) after applying $\boldsymbol{h C R}$ and $\boldsymbol{I C R}$ to compress the whole signal.

2) Percentage RMS difference (PRD):

$$
\operatorname{PRD}(\%)=100 \% \times \sqrt{\frac{\sum_{0}^{N-1}\left(\mathrm{y}_{\mathrm{i}}-\hat{\mathrm{y}}_{\mathrm{i}}\right)^{2}}{\sum_{0}^{N-1}\left(\mathrm{y}_{\mathrm{i}}\right)^{2}}}
$$

This is also most commonly used to evaluate the performance of an ECG compression method.

3) Percentage $R M S$ difference, normalized $(P R D N)$ :

$$
\operatorname{PRDN}(\%)=100 \% \times \sqrt{\frac{\sum_{0}^{N-1}\left(\mathrm{y}_{\mathrm{i}}-\hat{\mathrm{y}}_{\mathrm{i}}\right)^{2}}{\sum_{0}^{N-1}\left(\mathrm{y}_{\mathrm{i}}-\bar{y}\right)^{2}}}
$$

yis the average of the original data.

4) Root mean square error (RMS):

$$
\mathrm{RMS}=\sqrt{\frac{\sum_{0}^{N-1}\left(\mathrm{y}_{\mathrm{i}}-\hat{\mathrm{y}}_{\mathrm{i}}\right)^{2}}{N-1}}
$$

5) Signal-to-noise ratio $(S N R)$ :

$$
\mathrm{SNR}=10 \times \log \left(\frac{\sum_{0}^{N-1}\left(y_{i}-\bar{y}\right)^{2}}{\sum_{0}^{N-1}\left(y_{i}-\hat{y}_{i}\right)^{2}}\right)
$$

\section{6) Peak Maximum Absolute Error(PMAE):}

Of note, we also proposed a new index to support the evaluation of the attenuation level of $\mathrm{P}, \mathrm{R}$ and $\mathrm{T}$ peaks known as the Peak Maximum Absolute Error (PMAE) presented below:

$$
\text { PMAE }=\frac{\mathrm{y}_{\text {peak }}-\hat{\mathrm{y}}_{\text {peak }}}{\Delta \mathrm{y}_{\max }} \times 100 \%
$$

With: $\quad \Delta \mathrm{y}_{\max }=\max \left(\mathrm{y}_{\mathrm{i}} \mid \mathrm{i}=\mathrm{n}_{1}, \ldots, \mathrm{n}_{2}\right)-$ $\min \left(y_{i} \mid i=n_{1}, \ldots, n_{2}\right) \quad$ (8)

$\mathrm{y}_{\text {peak }}$ is the $\mathrm{P}, \mathrm{R}$ or $\mathrm{T}$ peak of the original data, $\hat{y}_{\text {peak }}$ is the $\mathrm{P}, \mathrm{R}$ or $\mathrm{T}$ peak of the reconstructed data, $\mathrm{n}_{1}$ and $\mathrm{n}_{2}$ are the starting index and the final index of the corresponding duration containing this peak ( $\mathrm{P}$ wave, $\mathrm{QRS}$ or $\mathrm{T}$ wave), respectively. $\Delta y_{\max }$ is the maximum difference of this wave from index $\mathrm{n}_{1}$ to index $\mathrm{n}_{2}$ of the original data. This index aims to compare each peak's attenuation level tothe maximum difference of the wave holding that peak. Therefore, a high PMAE, about $10 \%$ and above, could lead to clear visibility of attenuation in shape and affect the outcome of the medical diagnosis. 


\subsection{Experiments with MIT-BIH arrhythmia database}

The first lead of all 48 MIT-BIH arrhythmia records with values ranging from 0 to 2048 were compressed and decompressed by the two-state algorithm, in which 4 different ratios of $\boldsymbol{h C R} /$ $\boldsymbol{l C R}$ from 2 to 5 were tested. These included (hCR-lCR) 2-2, 4-2, 6-2, 8-2, 10-2, 6-3, 9-3, 12-3, $15-3,8-4,12-4,16-4,20-4,10-5,15-5,20-5$ and 25-5, and two thresholds $\boldsymbol{T h r} \mathbf{1}=10$ and $\mathbf{T h r} \mathbf{2}=$ $0.3 \times \mathbf{T h r} \mathbf{l}=3$. To evaluate the whole signal reconstruction, CR (overall compression ratio $\boldsymbol{o} \boldsymbol{C R})$, PRD, PRDN, RMS and SNR were calculated for the full period of 30 minutes for each record. Moreover, to assess the influence of the selection of two compression ratios $(\boldsymbol{h} \boldsymbol{C R}$ and $\boldsymbol{l C R}$ ) in re-building the signal, 10 consecutive $\mathrm{P}$ waves, $T$ waves and QRS of each recording were surveyed through PRD, and 10 consecutive P, R and $\mathrm{T}$ peaks were assessed for their attenuation through PMAE. The overall performance of the algorithm in compressing and reconstructing all 48 arrythmia records is presented in Figure 8.

In terms of overall CR (oCR), although an increase in both $\boldsymbol{h} \boldsymbol{C R}$ and $\boldsymbol{l C R}$ led to an increase in $\boldsymbol{o C R}$, when $\boldsymbol{h} \boldsymbol{C R}$ was large enough $(\boldsymbol{l C R} \geq 15)$, the $\boldsymbol{o C R}$ showed no further signifcant improvements, such as in cases of $\boldsymbol{h C R}-\boldsymbol{l C R}$ (oCR)16-4 (14.125) versus 20-4 (14.046), or 15-5 (15.556) versus 20-5 (15.932) versus 25-5 (15.559). Generally, the increase in the ratio $\boldsymbol{h C R} / \boldsymbol{l C R}$ from 2 to 5 caused an increase on average by $0.6 \%$ in PRD, $1.5 \%$ in PRDN, 0.45 bit in RMS and a decrease on average by $2.75 \mathrm{~dB}$ in SNR in all cases of $\boldsymbol{l C R}$. Table 1 shows the detailed results of five indexes of each recording with two cases of $\boldsymbol{h} \boldsymbol{C R}-\boldsymbol{l C} \boldsymbol{R}=25-5$.

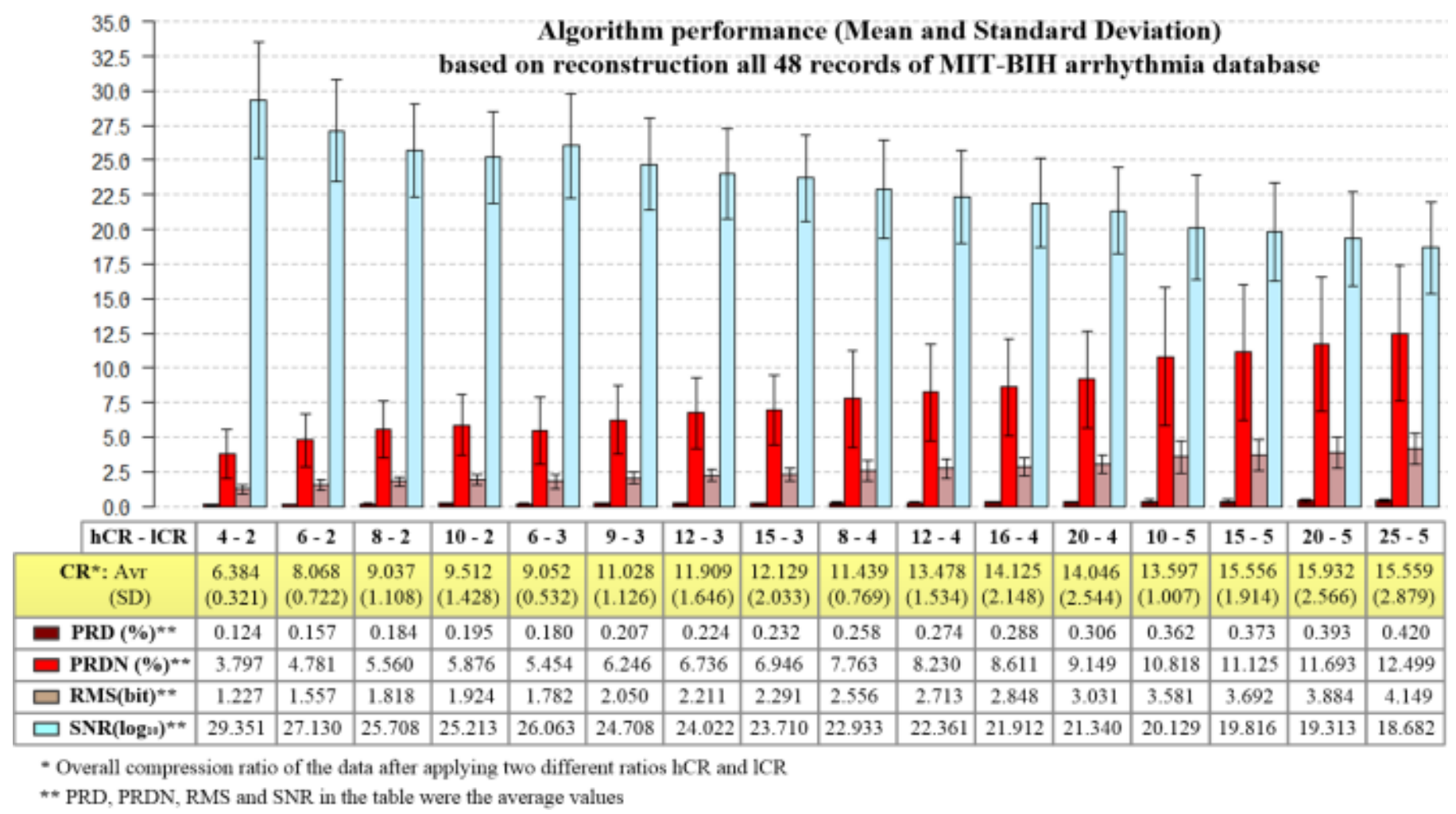

Figure 8. The overall performance of the proposed algorithm through five evaluation indexes of all 48 records of MIT$\mathrm{BIH}$ arrhythmia database

Refering to PRD boxplots of a total of $480 \mathrm{P}$ waves, QRS complexes and T waves of all 48 records (Figure 9), it seemed that reconstructions of QRS results were very stable among cases with the same $\boldsymbol{l C R}$, but there were a big difference in both the median value and the data 
range between $\boldsymbol{l C R}=2,3,4$ and 5. Except for some outliers, the PRD results of QRS were all smaller than $0.5 \%$ if $\boldsymbol{l C R}<4$ was selected and below $1 \%$ with $\boldsymbol{l C R}=4$.

With the highest $\boldsymbol{l C R}$ of 5 , only $75 \%$ of all QRScomplexes were re-built with PRD below $1 \%$, and this result will heavily affect medical diagnosis. In contrast, the PRD results of $\mathrm{P}$ waves and $\mathrm{T}$ waves expanded proportionally mostly to the rise in $\boldsymbol{h C R}$, but not in $\boldsymbol{l C R}$, and the level of the data's expansion was much lower in all cases with PRD being smaller than $0.75 \%$, except for a very small number of outliers.

\section{PRD(\%) all 48 records of MIT-BIH arrhythmia database}

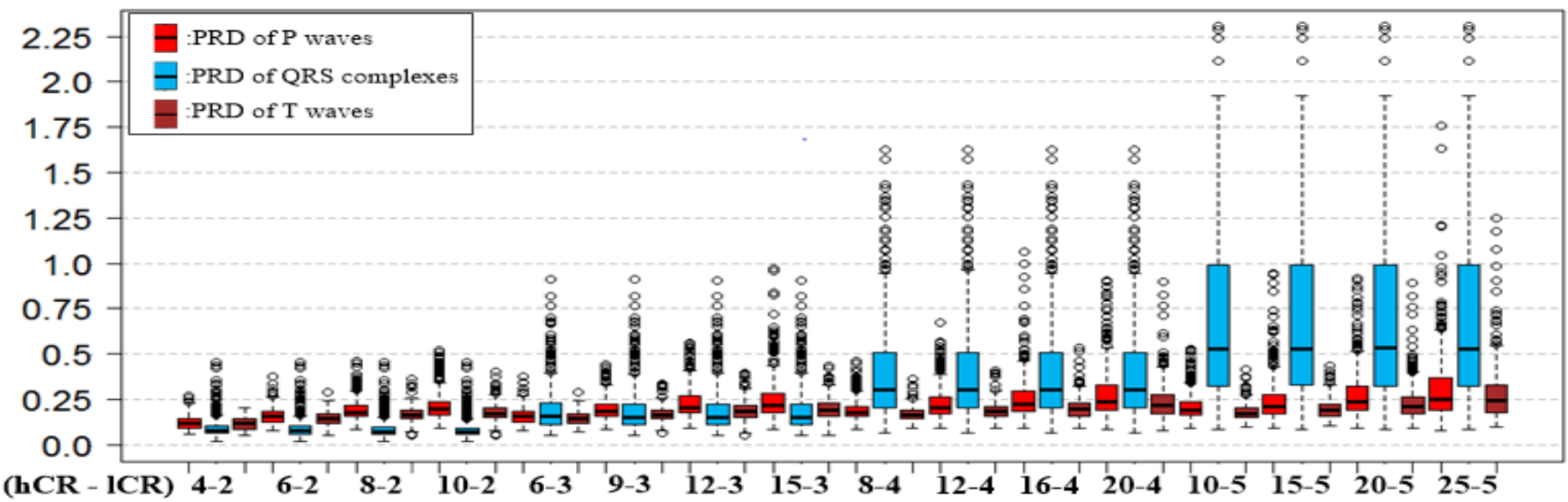

Figure 9. PRD of a total of $480 \mathrm{P}$ waves, $\mathrm{T}$ waves and QRS complexes of all 48 records of MIT-BIH arrhythmia database

\section{PMAE of $P$ peaks, $R$ peaks and $T$ peaks of all 48 records of MIT-BIH arrhythmia database (evaluation of peak attenuation)}

PMAE(\%)

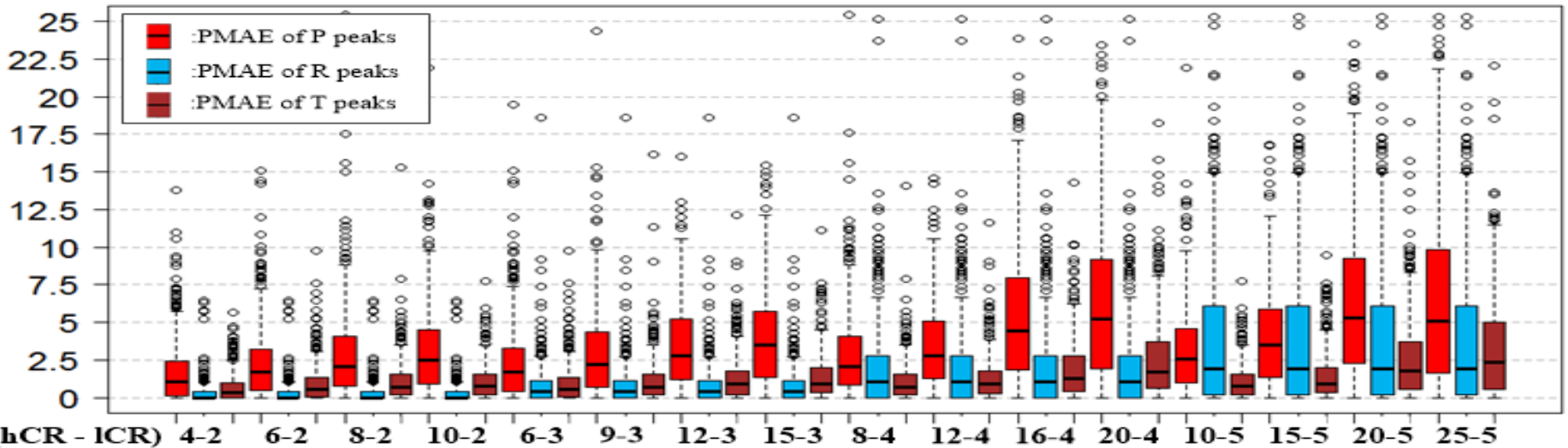

Figure 10. PMAE of a total of $480 \mathrm{P}, \mathrm{R}$ and $\mathrm{T}$ peaks of all 48 records of all 48 records of MIT- BIH arrhythmia database 
In terms of attenuation of the peaks (Figure $10)$, the PMAE of $\mathrm{R}$ peaks were almost under $10 \%$ (a value that could lead to medical misintepretation) except for a very small number of outliers with $\boldsymbol{l C} \boldsymbol{R} \leq 4$. In contrast, higher PMAE results of both the median value and the range were found in $T$ peaks and especially in $P$ peaks when compared to $\mathrm{R}$ peaks within the same cases. Nevertheless, with $\boldsymbol{l} \boldsymbol{R} \leq 4$ and $\boldsymbol{h} \boldsymbol{C} \leq 10$, all peaks could obtain less than 10\% PMAE as shown in Figure 10.
Figure 11, 12, 13 and 14 respectively exhibit the reconstruction of record 113 (with worst PRD), record 117, record 119 and record 112 (with best PRD) after compression by the proposed algorithm with four $\boldsymbol{h} \boldsymbol{C R}-\boldsymbol{l C R}$ of $10-2$, 15-3, 20-4 and 25-5. The differences became visually clear when $\mathbf{I C R}>3$ in record 113 however, no significant differences were seen between all 4 cases for other 3 records.

Table 1. Overall CR, PRD, PRDN, RMS, SNR of 48 records of MIT-BIH arrhythmia after decompressing with $\mathrm{hCR} / \mathrm{lCR}=25-5$

\begin{tabular}{|c|c|c|c|c|c|c|c|c|c|c|c|}
\hline Rec. & CR & PRD & PRDN & RMS & SNR & Rec. & CR & PRD & PRDN & RMS & SNR \\
\hline 100 & 17.538 & 0.418 & 21.023 & 4.154 & 13.545 & 201 & 19.456 & 0.239 & 12.126 & 2.409 & 18.325 \\
\hline 101 & 18.600 & 0.410 & 15.273 & 4.083 & 16.321 & 202 & 17.018 & 0.270 & 8.927 & 2.719 & 20.985 \\
\hline 102 & 15.881 & 0.491 & 25.145 & 4.903 & 11.989 & 203 & 11.444 & 0.440 & 8.743 & 4.435 & 21.166 \\
\hline 103 & 17.353 & 0.423 & 12.859 & 4.236 & 17.815 & 205 & 15.872 & 0.340 & 16.810 & 3.384 & 15.488 \\
\hline 104 & 14.667 & 0.642 & 25.078 & 6.428 & 12.013 & 207 & 17.503 & 0.337 & 9.366 & 3.395 & 20.568 \\
\hline 105 & 14.225 & 0.410 & 9.916 & 4.113 & 20.072 & 208 & 12.299 & 0.447 & 9.126 & 4.506 & 20.793 \\
\hline 106 & 15.063 & 0.469 & 12.549 & 4.725 & 18.027 & 209 & 12.136 & 0.486 & 17.869 & 4.903 & 14.957 \\
\hline 107 & 10.393 & 0.543 & 6.215 & 5.458 & 24.130 & 210 & 15.220 & 0.271 & 10.226 & 2.733 & 19.805 \\
\hline 108 & 16.339 & 0.427 & 13.875 & 4.274 & 17.155 & 212 & 11.277 & 0.585 & 17.414 & 5.901 & 15.181 \\
\hline 109 & 13.945 & 0.305 & 5.990 & 3.058 & 24.450 & 213 & 10.402 & 0.435 & 6.361 & 4.370 & 23.929 \\
\hline 111 & 15.813 & 0.304 & 11.667 & 3.070 & 18.660 & 214 & 13.650 & 0.344 & 7.214 & 3.472 & 22.835 \\
\hline 112 & 15.859 & 0.301 & 7.235 & 1.655 & 22.811 & 215 & & 0.378 & 13.205 & 3.812 & 17.584 \\
\hline 113 & 17.297 & 0.718 & 17.148 & 7.241 & 15.315 & 217 & 11.624 & 0.481 & 7.699 & 4.854 & 22.270 \\
\hline 114 & 18.825 & 0.340 & 19.563 & 3.431 & 14.170 & 219 & 16.678 & 0.456 & 7.807 & 4.406 & 22.149 \\
\hline 115 & 17.925 & 0.519 & 13.607 & 5.060 & 17.324 & 220 & 17.502 & 0.628 & 18.682 & 6.090 & 14.571 \\
\hline 116 & 13.231 & 0.671 & 9.183 & 6.245 & 20.740 & 221 & 15.326 & 0.301 & 9.838 & 3.029 & 20.141 \\
\hline 117 & 21.069 & 0.331 & 12.679 & 3.102 & 17.938 & 222 & 15.969 & 0.394 & 20.925 & 3.977 & 13.586 \\
\hline 118 & 12.408 & 0.593 & 12.680 & 5.555 & 17.937 & 223 & 15.062 & 0.353 & 8.238 & 3.431 & 21.682 \\
\hline 119 & 15.946 & 0.551 & 9.427 & 5.167 & 20.512 & 228 & 16.001 & 0.354 & 10.093 & 3.577 & 19.919 \\
\hline 121 & 20.662 & 0.416 & 12.703 & 3.919 & 17.921 & 230 & 16.060 & 0.370 & 10.284 & 3.732 & 19.756 \\
\hline 122 & 14.504 & 0.375 & 9.408 & 3.523 & 20.529 & 231 & 19.985 & 0.438 & 15.888 & 4.422 & 15.978 \\
\hline 123 & 20.465 & 0.443 & 14.045 & 4.176 & 17.049 & 232 & 18.739 & 0.306 & 18.256 & 3.087 & 14.771 \\
\hline 124 & 19.561 & 0.281 & 5.599 & 2.647 & 25.037 & 233 & 12.244 & 0.373 & 6.771 & 3.767 & 23.386 \\
\hline 200 & 12.586 & 0.398 & 10.387 & 4.041 & 19.669 & 234 & 14.836 & 0.313 & 9.138 & 3.157 & 20.782 \\
\hline
\end{tabular}




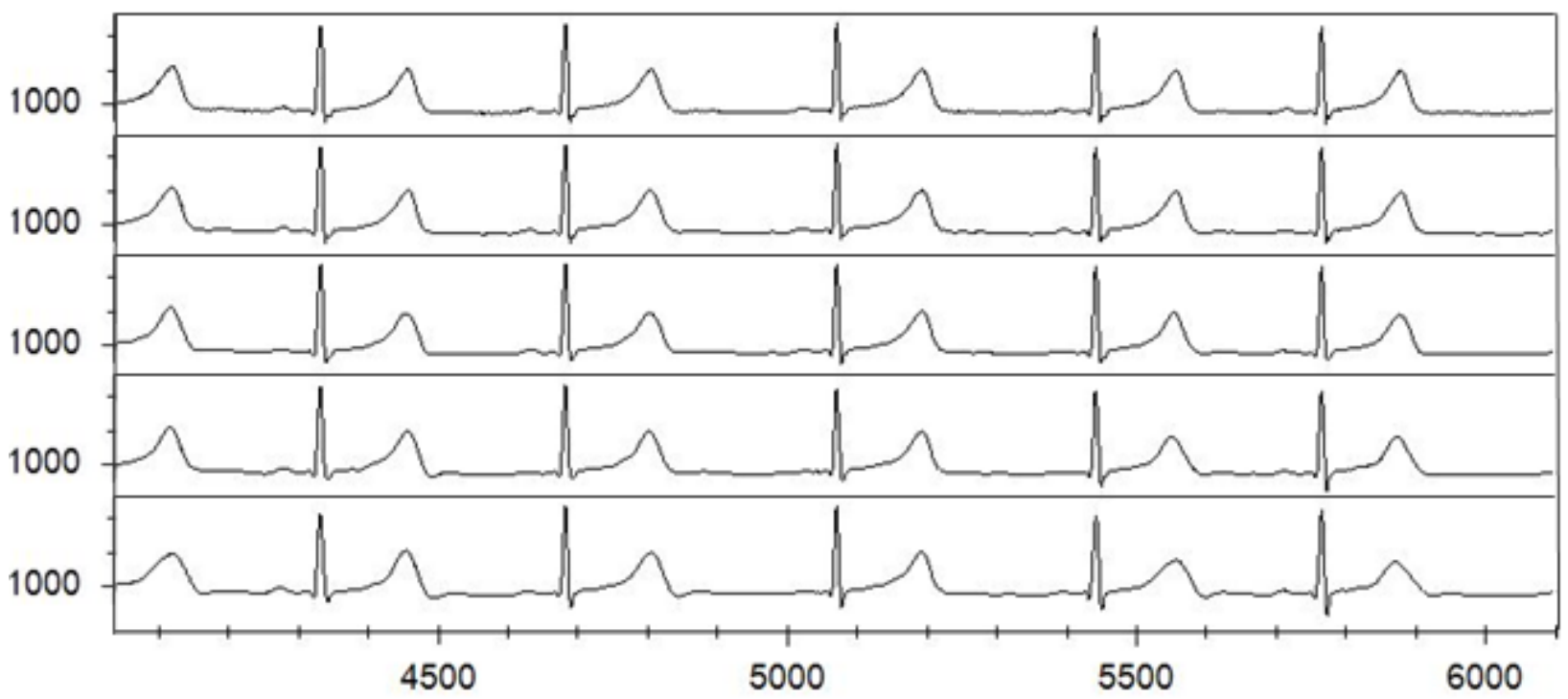

(a)

(b)

(c)

(d)

(e)

Figure 11. Reconstruction of record 113 (worst PRD) at different compression ratios. (a) Original data, (b) hCR/ICR $=10-2, \mathbf{C R}=10.72, \mathrm{PRD}=0.179 \%$, (c) hCR/ICR $=15-3, \mathrm{CR}=13.73, \mathrm{PRD}=0.264 \%$ (d) hCR/ICR $=20-4, \mathrm{CR}=15.86, \mathrm{PRD}=0.453 \%$ (e) $\mathbf{h C r} / \mathbf{l C R}=25-5, \mathrm{CR}=17.29, \mathrm{PRD}=0.718 \%$.

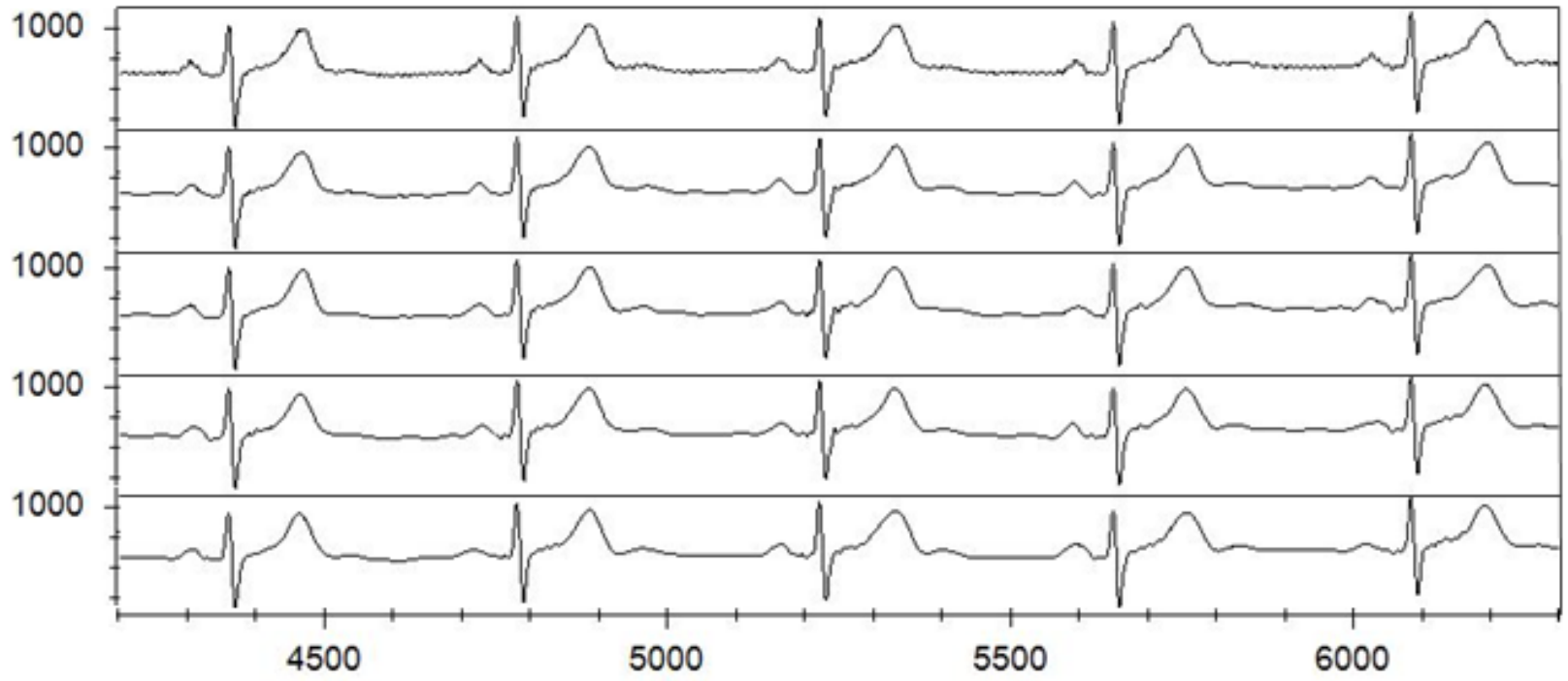

(a)

Figure 12. Reconstruction of record 117 at different compression ratios. (a) Original data, (b) $\mathbf{h C R} / \mathbf{l C R}=10-2$, $\mathrm{CR}=11.86, \mathrm{PRD}=0.213 \%$, (c) $\mathbf{h C R} / \mathbf{l C R}=15-3, \mathrm{CR}=15.78, \mathrm{PRD}=0.225 \%$ (d) $\mathbf{h C R} / \mathbf{l C R}=20-4, \mathrm{CR}=18.82$, $\mathrm{PRD}=0.254 \%$ (e) $\mathbf{h C r} / \mathbf{l C R}=25-5, \mathrm{CR}=21.06, \mathrm{PRD}=0.331 \%$.

\subsection{Experiments with $\mathrm{CU}$ ventricular tachyarrhythmia database}

A period of 1-minute of each record in 9 ventricular tachyarrhythmia records (CU04, CU06, CU07, CU10, CU12, CU16, CU20, CU22, CU24), which do not have clear PQRST shapes and have values ranging from 0 to 4095 , was extracted, compressed and decompressed by our algorithm with the same parameters used in MITBIH arrythmia database. For evaluation, the overall CR, PRD, PRDN, RMS and SNR were chosen.

It can be seen that there were minor variances (small standard deviations) in all five indexes with all values of $\boldsymbol{l C R}$ ranging from 2 to 5 in 9 records. Moreover, all recordings experienced the same tendency of continous increase in PRD (an average of $\sim 0.12 \%)$, PRDN $(\sim 2 \%)$ and RMS ( 6 bits), and a decrease of SNR $(\sim 6 \mathrm{~dB})$ when increasing $\boldsymbol{l} \boldsymbol{C R}$ by 1 , except for CU04 and CU20 
whose indexes were relatively consistent when changing $\boldsymbol{l C R}$.

There were also examples of the reconstruction of CU04 (best PRD) (Figure 15) and CU12 (worst PRD) (Figure 16) with $\boldsymbol{h C R}$ $\boldsymbol{I C R}=10-2,15-3,20-4$ and 25-5. It is difficult to visually recognize the real differences in the reconstruction in all five cases, including record CU12 although its PRD was $3.914 \%$ at the highest compression ratios (when $\boldsymbol{h C} \boldsymbol{R}-\boldsymbol{l C R}=25$ $5)$.

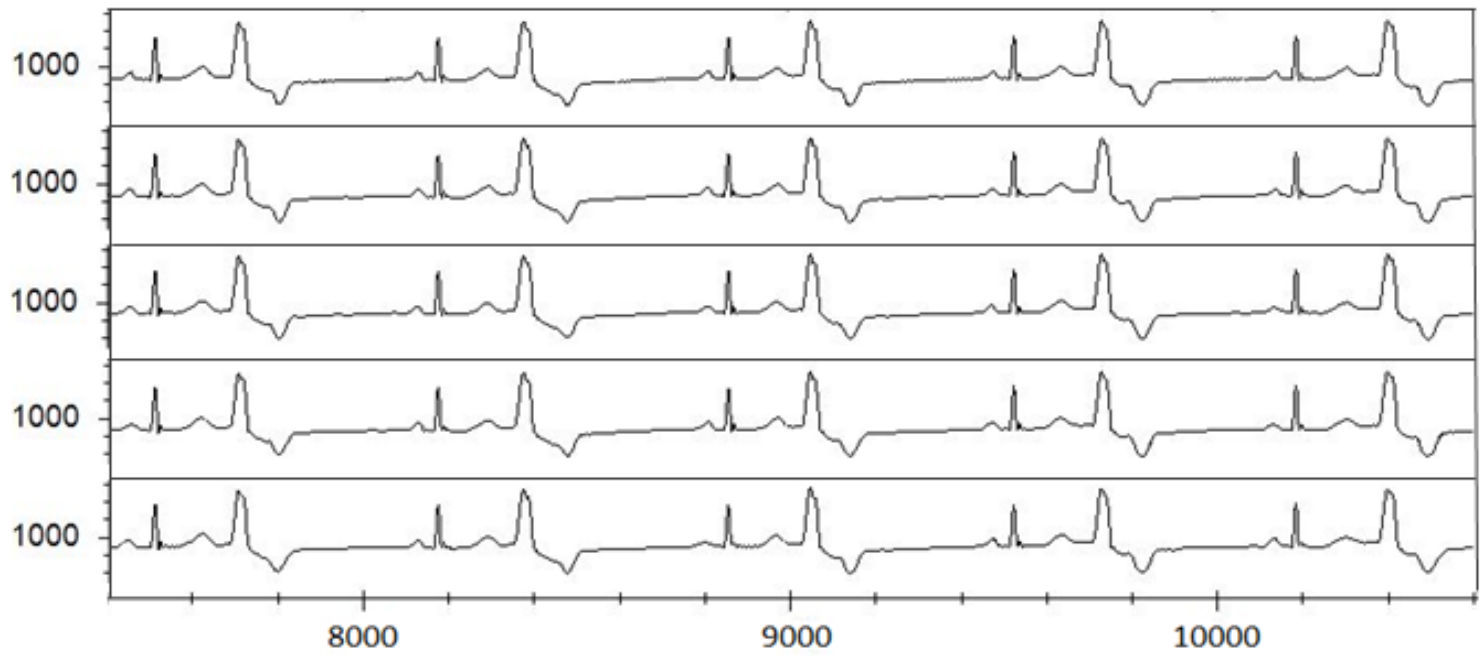

(a)

Figure 13. Reconstruction of record 119 at different compression ratios. (a) Original data, (b) $\mathbf{h C R} / \mathbf{I C R}=10-2$, $\mathrm{CR}=10.08, \mathrm{PRD}=0.226 \%$, (c) $\mathbf{h C R} / \mathbf{l C R}=15-3, \mathrm{CR}=12.81, \mathrm{PRD}=0.282 \%$ (d) $\mathbf{h C R} / \mathbf{I C R}=20-4, \mathrm{CR}=14.56$, $\mathrm{PRD}=0.390 \%$ (e) $\mathbf{h C r} / \mathbf{l C R}=25-5, \mathrm{CR}=15.94, \mathrm{PRD}=0.551 \%$.

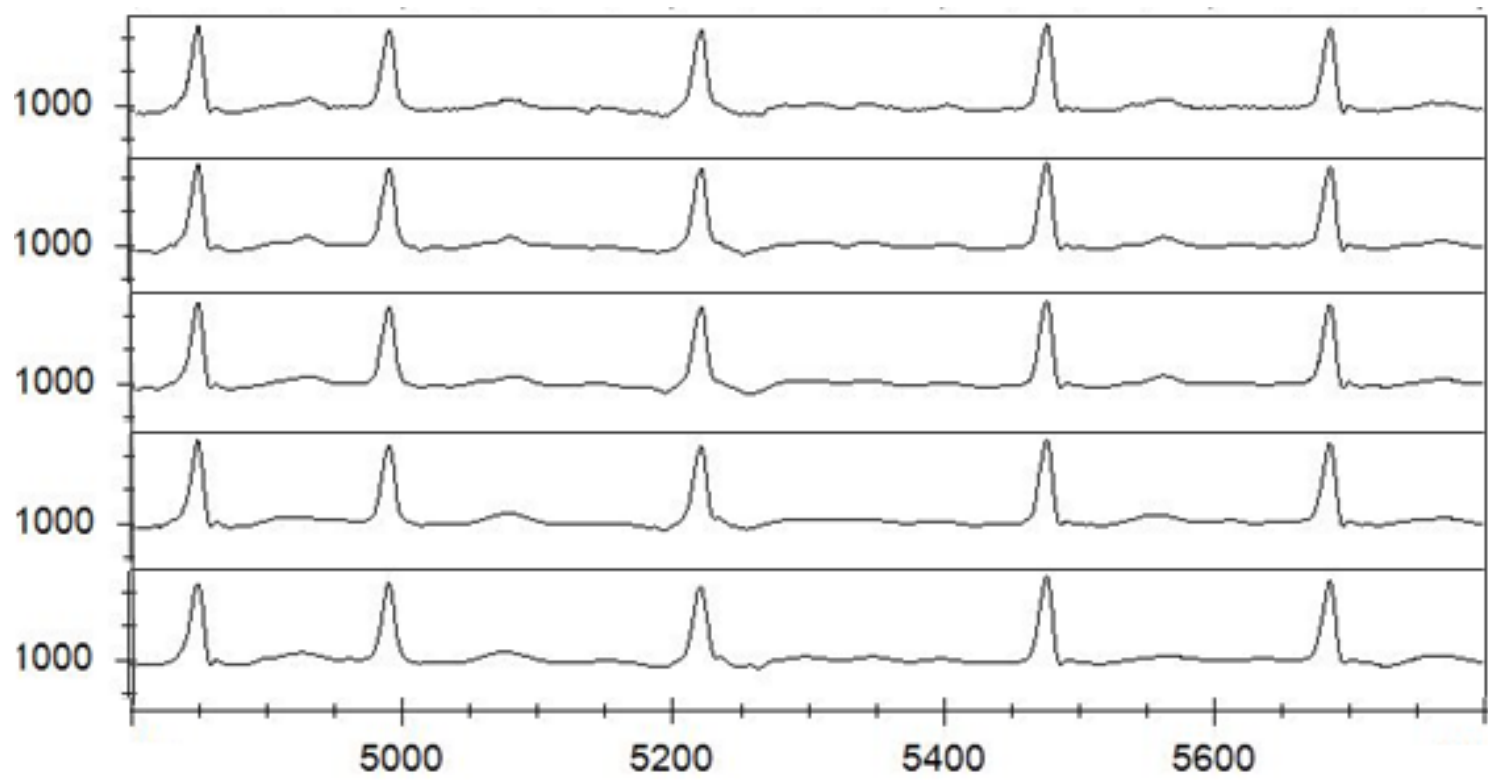

(a)

(b)

(c)

(d)

Figure 14. Reconstruction of record 201 (best PRD) at different compression ratios. (a) Original data, (b) hCR/ICR $=10-2, \mathbf{C R}=11.33, \mathrm{PRD}=0.129 \%$, (c) hCR/ICR $=15-3, \mathrm{CR}=14.75, \mathrm{PRD}=0.152 \%$ (d) $\mathbf{h C R} / \mathbf{l C R}=$ $20-4, \mathrm{CR}=17.37, \mathrm{PRD}=0.188 \%$ (e) $\mathbf{h C r} / \mathbf{l C R}=25-5, \mathrm{CR}=19.45, \mathrm{PRD}=0.239 \%$ 


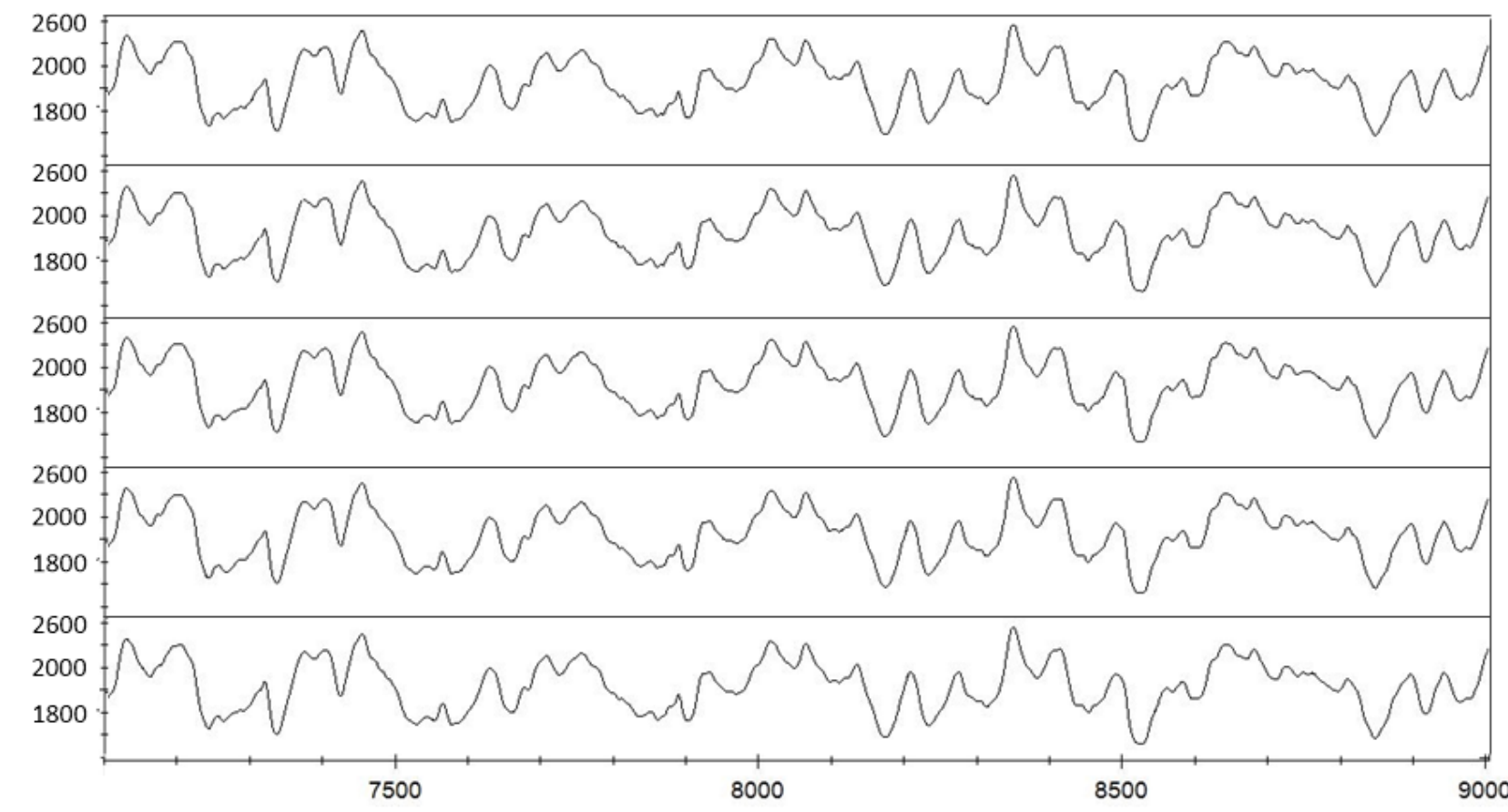

(a)

(b)

(c)

(d)

(e)

Figure 15. Reconstruction of record CU04 (best PRD) at different compression ratios. (a) Original data, (b) hCR-ICR $=10-2, \mathrm{CR}=3.99, \mathrm{PRD}=0.022 \%$, (c) hCR-ICR $=15-3, \mathrm{CR}=5.98, \mathrm{PRD}=0.034 \%$, (d) hCR-ICR $=20-4, \mathrm{CR}=7.91$, $\mathrm{PRD}=0.048 \%$, (e) hCR-ICR $=25-5$.

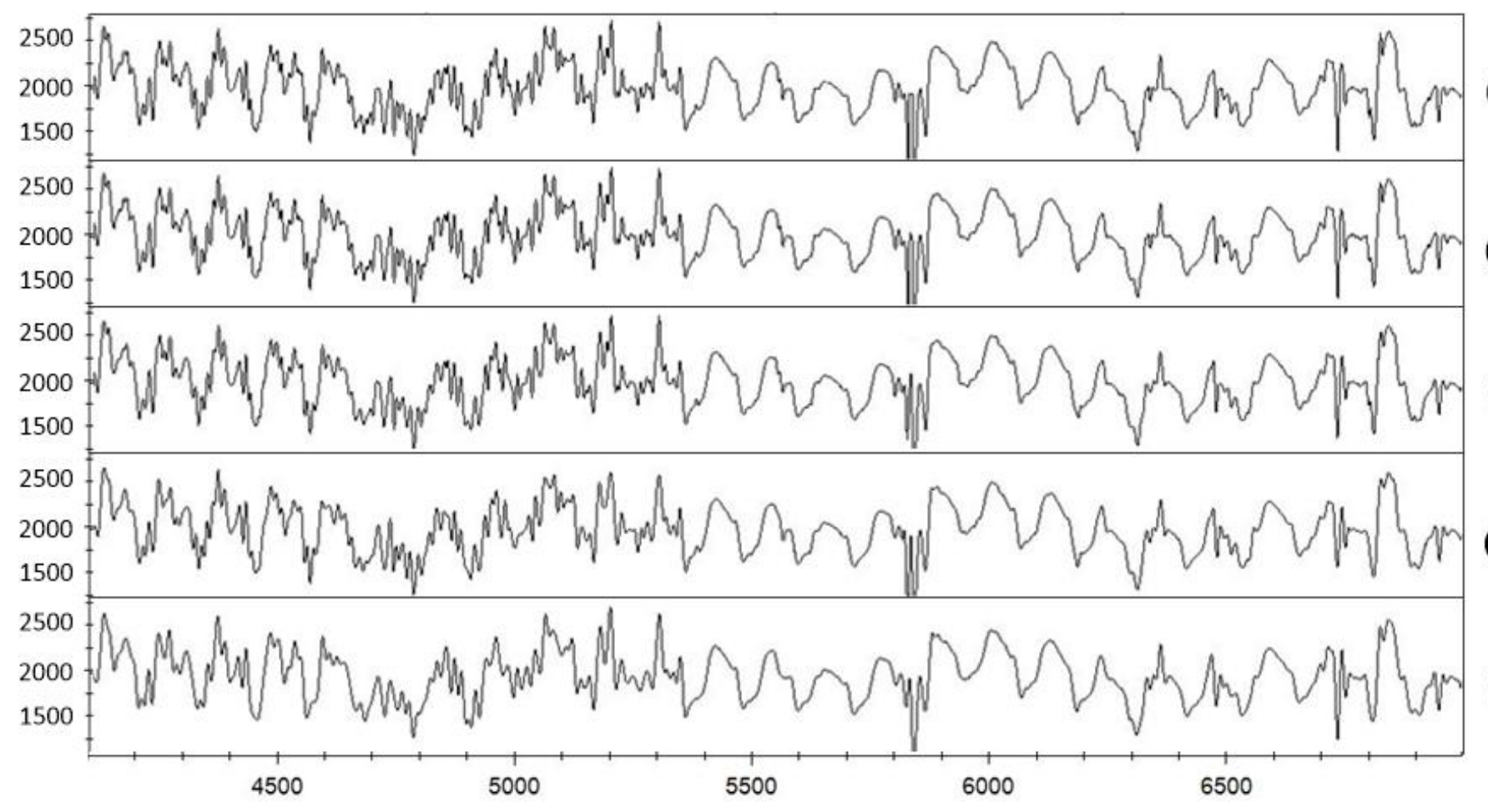

(a)

Figure 16. Reconstruction of record CU12 (worst PRD) at different compression ratios. (a) Original data, (b) hCR-lCR $=10-2, \mathrm{CR}=3.37, \mathrm{PRD}=0.938 \%$, (c) hCR-lCR $=15-3, \mathrm{CR}=4.783, \mathrm{PRD}=1.542 \%$, (d) hCR-lCR $=20-4, \mathrm{CR}=6.09$, $\mathrm{PRD}=2.803 \%,(\mathrm{e}) \mathrm{hCR}-\mathrm{lCR}=25-5, \mathrm{CR}=7.24, \mathrm{PRD}=3.914 \%$. 
Table 2. Overall CR, PRD, PRDN, RMS and SNR of 10 reconstructed records (CU ventricular tachyarrhythmia database). Results of cases having the same lCR were grouped in one group expressed by mean value and standard deviation.

\begin{tabular}{|c|c|c|c|c|c|c|c|c|c|c|c|}
\hline \multirow[t]{2}{*}{ Rec. } & \multirow[t]{2}{*}{ ICR } & \multicolumn{2}{|l|}{ CR } & \multicolumn{2}{|c|}{ PRD } & \multicolumn{2}{|l|}{ PRDN } & \multicolumn{2}{|l|}{ RMS } & \multicolumn{2}{|l|}{ SNR } \\
\hline & & $M$ & $S D$ & $M$ & $S D$ & $M$ & $S D$ & $M$ & $S D$ & $M$ & $S D$ \\
\hline \multirow[t]{4}{*}{ CU04 } & $2^{\mathrm{a}}$ & 3.953 & 0.065 & 0.023 & 0.002 & 0.441 & 0.046 & 0.949 & 0.100 & 47.16 & 0.936 \\
\hline & $3^{b}$ & 5.948 & 0.057 & 0.031 & 0.005 & 0.595 & 0.009 & 1.282 & 0.193 & 44.58 & 1.277 \\
\hline & $4^{\mathrm{c}}$ & 7.900 & 0.036 & 0.046 & 0.004 & 0.875 & 0.074 & 1.885 & 0.160 & 41.18 & 0.720 \\
\hline & $5^{\mathrm{d}}$ & 9.625 & 0.012 & 0.067 & 0.001 & 1.280 & 0.016 & 2.759 & 0.036 & 37.85 & 0.112 \\
\hline \multirow[t]{4}{*}{ CU06 } & 2 & 3.916 & 0.010 & 0.065 & 0.001 & 0.949 & 0.001 & 2.693 & 0.001 & 40.46 & 0.004 \\
\hline & 3 & 5.492 & 0.012 & 0.153 & 0.001 & 2.213 & 0.001 & 6.281 & 0.001 & 33.10 & 0.001 \\
\hline & 4 & 6.769 & 0.008 & 0.295 & 0.001 & 4.279 & 0.001 & 12.15 & 0.001 & 27.37 & 0.001 \\
\hline & 5 & 7.888 & 0.009 & 0.426 & 0.001 & 6.183 & 0.001 & 17.55 & 0.001 & 24.17 & 0.001 \\
\hline \multirow[t]{4}{*}{ CU07 } & 2 & 3.862 & 0.071 & 0.068 & 0.001 & 1.147 & 0.014 & 1.407 & 0.018 & 38.81 & 0.110 \\
\hline & 3 & 5.481 & 0.071 & 0.156 & 0.001 & 2.620 & 0.022 & 3.125 & 0.026 & 31.63 & 0.071 \\
\hline & 4 & 6.931 & 0.024 & 0.367 & 0.001 & 6.157 & 0.005 & 7.554 & 0.006 & 24.21 & 0.007 \\
\hline & 5 & 8.279 & 0.004 & 0.792 & 0.003 & 13.29 & 0.043 & 16.30 & 0.052 & 17.53 & 0.028 \\
\hline \multirow[t]{4}{*}{ CU10 } & 2 & 3.736 & 0.001 & 0.112 & 0.001 & 1.002 & 0.003 & 2.640 & 0.010 & 39.98 & 0.029 \\
\hline & 3 & 5.084 & 0.001 & 0.481 & 0.001 & 3.963 & 0.001 & 10.44 & 0.001 & 28.04 & 0.001 \\
\hline & 4 & 6.258 & 0.001 & 0.978 & 0.001 & 8.049 & 0.001 & 21.23 & 0.001 & 21.89 & 0.001 \\
\hline & 5 & 7.358 & 0.001 & 1.581 & 0.001 & 13.01 & 0.001 & 34.33 & 0.001 & 17.71 & 0.001 \\
\hline \multirow[t]{4}{*}{ CU12 } & 2 & 3.372 & 0.003 & 0.938 & 0.001 & 4.221 & 0.001 & 20.69 & 0.001 & 27.49 & 0.001 \\
\hline & 3 & 4.785 & 0.003 & 1.542 & 0.001 & 6.937 & 0.001 & 34.01 & 0.001 & 23.18 & 0.001 \\
\hline & 4 & 6.092 & 0.002 & 2.803 & 0.001 & 12.61 & 0.001 & 61.82 & 0.001 & 17.99 & 0.001 \\
\hline & 5 & 7.239 & 0.001 & 3.914 & 0.001 & 16.80 & 0.001 & 82.37 & 0.001 & 15.50 & 0.001 \\
\hline \multirow[t]{4}{*}{ CU16 } & 2 & 2.797 & 0.001 & 0.356 & 0.001 & 1.266 & 0.001 & 7.592 & 0.001 & 37.95 & 0.001 \\
\hline & 3 & 3.737 & 0.001 & 1.073 & 0.001 & 3.817 & 0.001 & 22.90 & 0.001 & 28.36 & 0.001 \\
\hline & 4 & 4.711 & 0.001 & 1.862 & 0.001 & 6.625 & 0.001 & 39.74 & 0.001 & 23.58 & 0.001 \\
\hline & 5 & 5.708 & 0.001 & 2.895 & 0.001 & 10.12 & 0.001 & 61.66 & 0.001 & 19.74 & 0.001 \\
\hline \multirow[t]{4}{*}{ CU20 } & 2 & 4.193 & 0.052 & 0079 & 0.004 & 0.399 & 0.022 & 1.634 & 0.009 & 48.00 & 0.474 \\
\hline & 3 & 5.876 & 0.034 & 0.129 & 0.006 & 0.655 & 0.031 & 2.687 & 0.129 & 43.88 & 0.415 \\
\hline & 4 & 7.535 & 0.049 & 0.222 & 0.007 & 1.125 & 0.036 & 4.612 & 0.147 & 38.98 & 0.275 \\
\hline & 5 & 9.011 & 0.081 & 0.292 & 0.007 & 1.478 & 0.033 & 6.057 & 0.138 & 36.61 & 0.196 \\
\hline \multirow[t]{4}{*}{ CU22 } & 2 & 3.778 & 0.009 & 0.964 & 0.001 & 6.893 & 0.001 & 20.30 & 0.002 & 23.23 & 0.001 \\
\hline & 3 & 5.163 & 0.007 & 1.658 & 0.001 & 11.79 & 0.001 & 34.90 & 0.002 & 18.52 & 0.001 \\
\hline & 4 & 6.316 & 0.007 & 1.787 & 0.010 & 12.54 & 0.003 & 37.72 & 0.010 & 18.03 & 0.002 \\
\hline & 5 & 7.363 & 0.009 & 2.418 & 0.001 & 16.97 & 0.001 & 51.02 & 0.008 & 15.41 & 0.001 \\
\hline \multirow[t]{4}{*}{ CU24 } & 2 & 3.933 & 0.101 & 0.606 & 0.001 & 5.033 & 0.001 & 12.69 & 0.001 & 25.95 & 0.001 \\
\hline & 3 & 5.398 & 0.118 & 1.162 & 0.001 & 9.665 & 0.001 & 24.33 & 0.001 & 20.30 & 0.001 \\
\hline & 4 & 6.749 & 0.135 & 1.636 & 0.010 & 13.59 & 0.001 & 34.26 & 0.001 & 17.34 & 0.001 \\
\hline & 5 & 8.081 & 0.152 & 1.923 & 0.001 & 15.98 & 0.001 & 40.29 & 0.001 & 15.93 & 0.001 \\
\hline
\end{tabular}

Am. J. Biomed. Sci. 2016, 8(1), 1-23; doi: 10.5099/aj160100001 @ 2016 by NWPII. All rights reserved 


\section{Discussion}

\subsection{The influence of choosing compression ratios on the algorithm's performance}

As seen in Figure 8, the overall performance of the algorithm applied in MIT-BIH arrhythmia database showed its dependence on the selection of $\boldsymbol{h C R}$ and $\boldsymbol{l C R}$. Although $\boldsymbol{l C R}$ had a greater impact on the overall results than $\boldsymbol{h C R}$, their roles were determined more clearlywhen looking at the reconstruction of each feature including $\mathrm{P}$ wave, QRS complex, $T$ wave and their peaks. While $\mathrm{P}$ and $\mathrm{T}$ waves were mostly affected by $\boldsymbol{h C R}$, the peak of $\boldsymbol{I C R}$ completely influenced the reconstruction of QRS complexes. However, despite the fact that the $\mathrm{R}$ peaks were maintained very well at $\boldsymbol{l} \boldsymbol{C R}=4$ with PAME $<10 \%$, the shapes of QRS complexes were only reconstructed well with $\boldsymbol{l C R}<4$ with PRD < $0.75 \%$. Therefore, based on the results, it seems that $\boldsymbol{l C R}=3$ should be the highest possible CR applied for complex durations to avoid any significant errors. Regarding $\boldsymbol{h} \boldsymbol{C R}$, although the shape of $\mathrm{P}$ and $\mathrm{T}$ waves were well preserved even at the highest $\boldsymbol{h C R}$ of 25 with PRD $<0.75 \%$ except for very few cases, the PMAE of P and T peaks started to exceed $10 \%$ at $\boldsymbol{h C R}>10$. However, it is important to note that because the $60 \mathrm{~Hz}$ noises are still present in all records, many $\mathrm{P}$ and $\mathrm{T}$ peaks are not quite correctly detected and this could have affected the PMAE results. Hence, $\boldsymbol{h C R}$ could be expanded to 15 with most of the $\mathrm{P}$ peaks were attenuated by less than $12.5 \%$ of the waves maximum. Therefore, $\boldsymbol{l C R}=3$ and $\boldsymbol{h} \boldsymbol{C R}=$ 15 corresponding with PMAE $<10 \%$, PRD < $0.75 \%$ should be the limitations for the reconstruction of 11-bit ECG signals (value ranging from 0 to 2047). This is for critical applications that are needed to preserve the ECG signals well for diagnosis and critical treatment.

In $\mathrm{CU}$ ventricular tachyarrhythmia database, which offered more difficult curves with unclear PQRST, the role of $\boldsymbol{l C R}$ was shown to be dominant over $\boldsymbol{h C R}$ since all indexes were determined solely by $\boldsymbol{I C R}$. Meanwhile, the change of $\boldsymbol{h} \boldsymbol{C R}$ only created a very small variance. In addition, an increase by 1 unit in $\boldsymbol{l C R}$ also heavily affected the performance of the algorithm. It seemed that $\boldsymbol{l} \boldsymbol{C R}=3$ should be a safe choice for such difficult conditions such as $\mathrm{CU}$ ventricular tachyarrhythmia.

\subsection{The versatility of the algorithm}

The proposed algorithm was proven to be applicable for different kinds of ECG without depending on detecting or extracting any features of ECG. The results obtained from the assessment of MIT-BIH arrhythmia and CU ventricular tachyarrhythmia databases were also very positive with an acceptable level of error at moderate compression ratios. Moreover, the algorithm also offers an extremely low-cost computational compressing and decompressing method. Specifically, with $\mathrm{N}$ being the size of original data and $\mathrm{M}$ being the size of compressed data, there are only $\mathrm{N}$ equations that need to be calculated in the compressing method for finding the first derivative of the signal, with only one operation (-) in each equation, and $M$ equations in minimum to compress and store data. In the decompressing method, the time of calculation is nearly equal to the time of calculating the inverse difference ( $2 \mathrm{M}$ equations) and executing Cubic Spline Interpolation $(\mathrm{O}(\mathrm{M})$ equations in minimum if using LU decomposition to solve), since the first procedure of re-classifying state consumes a very short time. This will provide redundant time for the system to implement other digital processing if needed. Besides that, the compressed package can stop at any size (number of bytes) due to its block-unit processing mechanism without affecting the reconstruction at the receiver. Therefore, the algorithm is very suitable for use in many wireless applications as a step, such as an optimization solution to handle congested network as seen in ECG data.

\subsection{Performance comparison}

The proposed two-state algorithm was compared to other loss-type methods, which were also applied in MIT-BIH arrhythmia database in cases of CR $<25$ (table 3). Together, the results prove the great performance of our proposed algorithm with $\mathrm{CR}<25$ compared to many other methods, even including some TD methods which exhibited very promising results. However, as be seen in comparison with the Miaou et. al. algorithm[32] at CR > 18 which has far excellent 
performance, the proposed algorithm cannot ensure the quality of reconstruction at high $\mathrm{CR}$ as perfectly as some TD methods or $\mathrm{H}$ methods containing error minimization mechanism embedded in. In exchange, those methods are much more complex compared to the proposed algorithm and cannot adapt various sizes of the compressed packages like the proposed algorithm does.

Table 3. Performance comparison of different loss-type ECG compression schemes in record 100, 117 and 119 . In each record, the similarity of CR produced by different methods was grouped in 1 group and the order ranges from highest PRD (at the top of each group) to lowest PRD (at the bottom of the corresponding group). The proposed method was abbreviated as Proposed (hCR-lCR) and was highlighted in bold.

\begin{tabular}{|c|c|c|c|c|c|c|c|}
\hline Record & Method & CR & PRD & Record & Method & $\mathbf{C R}$ & PRD \\
\hline 100 & $\begin{array}{l}\text { Husoy et. } \\
\text { al.[27] }\end{array}$ & $23.5: 1$ & 12 & 101 & $\begin{array}{c}\text { Proposed } \\
(28-7)\end{array}$ & 23.7:1 & $16.19 *$ \\
\hline 100 & Lee et. al.[47] & $24: 1$ & 8.10 & 101 & $\begin{array}{l}\text { Miaou et.al. } \\
(\varepsilon=5 \%)[32]\end{array}$ & $25.4: 1$ & $8.97 *$ \\
\hline 100 & $\begin{array}{l}\text { Chou et. al. } \\
\text { app. } 2 \text { [46] }\end{array}$ & $24: 1$ & 4.06 & 101 & $\begin{array}{c}\text { Miaou et.al. } \\
(\varepsilon=10 \%)[32]\end{array}$ & 24.8:1 & $8.89 *$ \\
\hline 100 & $\begin{array}{l}\text { Filho et. al. } \\
\text { app.3 [48] }\end{array}$ & $24: 1$ & 3.95 & 101 & $\begin{array}{c}\text { Proposed } \\
(32-4)\end{array}$ & 17.6:1 & $8.21 *$ \\
\hline 100 & $\begin{array}{l}\text { SangJoon Lee } \\
\text { et. al. [29] }\end{array}$ & $23: 1$ & 1.94 & 101 & $\begin{array}{l}\text { Miaou et.al. } \\
\quad(\varepsilon=5 \%)\end{array}$ & 19.3:1 & $5.98 *$ \\
\hline 100 & $\begin{array}{c}\text { Proposed } \\
(30-10)\end{array}$ & 24.5:1 & 1.29 & 101 & $\begin{array}{l}\text { Miaou et.al. } \\
(\varepsilon=10 \%)\end{array}$ & 18.8:1 & $5.9 *$ \\
\hline 100 & $\begin{array}{c}\text { Istepanian et. al. } \\
{[30]}\end{array}$ & $18.3: 1$ & 0.60 & 101 & $\begin{array}{l}\text { Miaou et.al. } \\
\quad(\varepsilon=5 \%)\end{array}$ & $9.73: 1$ & $2.98 *$ \\
\hline 100 & $\begin{array}{c}\text { Proposed } \\
(18-6)\end{array}$ & 18.8:1 & 0.57 & 101 & $\begin{array}{l}\text { Miaou et.al. } \\
(\varepsilon=10 \%)\end{array}$ & $9.33: 1$ & $2.98 *$ \\
\hline 100 & Kim et. al. [34] ${ }^{\mathrm{a}}$ & $15: 1$ & 0.46 & 101 & $\begin{array}{c}\text { Proposed } \\
(8-2) \\
\end{array}$ & 10.1:1 & $2.89 *$ \\
\hline 100 & $\begin{array}{l}\text { Proposed } \\
(\mathbf{1 0 - 5})^{\mathrm{a}}\end{array}$ & 14.4:1 & 0.37 & 103 & Kim. et. al. ${ }^{a}$ & $15: 1$ & 0.82 \\
\hline 100 & $\begin{array}{l}\text { Filhoet. al. } \\
\text { app.3 }\end{array}$ & $10: 1$ & 2.12 & 103 & $\begin{array}{c}\text { Proposed } \\
(16-4)^{\mathrm{a}} \\
\end{array}$ & 15.3:1 & 0.22 \\
\hline 100 & $\begin{array}{l}\text { SangJoon Lee } \\
\text { et. al. }\end{array}$ & $9.6: 1$ & 0.44 & 104 & Kim. et. al. ${ }^{\mathrm{a}}$ & $15: 1$ & 0.88 \\
\hline 100 & $\begin{array}{c}\text { Proposed } \\
(8-2)\end{array}$ & 9.9:1 & 0.14 & 104 & $\begin{array}{c}\text { Proposed } \\
(20-5)^{\mathrm{a}}\end{array}$ & 14.7:1 & 0.69 \\
\hline 100 & Istepanian et. al. & $8.1: 1$ & 0.58 & 107 & Kim. et. al. ${ }^{\mathrm{a}}$ & $15: 1$ & 1.42 \\
\hline 100 & $\begin{array}{c}\text { Proposed } \\
(6-2) \\
\end{array}$ & 8.6:1 & 0.13 & 107 & $\begin{array}{c}\text { Proposed } \\
(24-8)^{\mathrm{a}} \\
\end{array}$ & $15: 1$ & 0.94 \\
\hline 117 & $\begin{array}{l}\text { Proposed } \\
(25-5)^{b}\end{array}$ & 21.8:1 & $3.21 *$ & 109 & $\begin{array}{c}\text { Proposed } \\
(18-6)^{b}\end{array}$ & 16.9:1 & $5.11 *$ \\
\hline 117 & $\begin{array}{c}\text { Hsieh-Wei } \\
\text { Lee[37] }\end{array}$ & 22.2:1 & $2.6^{*}$ & 109 & Hsieh-Wei Lee & $17.4: 1$ & $4.53 *$ \\
\hline 117 & Gurkan[38] & 17.9:1 & $2.46^{*}$ & 109 & $\begin{array}{c}\text { Proposed } \\
(4-2)^{b}\end{array}$ & 10.4:1 & $2.83 *$ \\
\hline 117 & $\begin{array}{l}\text { Proposed } \\
(12-3)\end{array}$ & 18.7:1 & $2.39 *$ & 109 & Hsieh-Wei Lee ${ }^{b}$ & 10.7:1 & $2.76^{*}$ \\
\hline
\end{tabular}




\begin{tabular}{|c|c|c|c|c|c|c|c|}
\hline Record & Method & $\mathbf{C R}$ & PRD & Record & Method & $\mathbf{C R}$ & PRD \\
\hline 117 & $\begin{array}{c}\text { Proposed } \\
(12-3)^{b}\end{array}$ & 15.2:1 & $2.04 *$ & 109 & $\begin{array}{c}\text { Proposed } \\
(4-2)^{b}\end{array}$ & $6.4: 1$ & $1.95 *$ \\
\hline 117 & Hsieh-Wei Lee $^{b}$ & $14.2: 1$ & $1.86^{*}$ & 109 & Hsieh-Wei Lee $^{b}$ & $6.5: 1$ & $1.67 *$ \\
\hline 117 & $\begin{array}{c}\text { Chou et. al. } \\
\text { app. } 2\end{array}$ & $13: 1$ & 1.18 & 111 & $\begin{array}{c}\text { Miaou et.al. } \\
(\varepsilon=5 \%)\end{array}$ & 21.6:1 & $8.96^{*}$ \\
\hline 117 & $\begin{array}{l}\text { Eddie B.L et. al. } \\
\text { app. } 3\end{array}$ & $13: 1$ & 1.07 & 111 & $\begin{array}{c}\text { Proposed } \\
(18-6)\end{array}$ & 20.5:1 & 8.9* \\
\hline 117 & $\begin{array}{l}\text { SangJoon Lee } \\
\text { et. al. }\end{array}$ & 12.6:1 & 0.43 & 111 & $\begin{array}{l}\text { Miaou et.al. } \\
(\varepsilon=10 \%)\end{array}$ & 20.6:1 & $8.73^{*}$ \\
\hline 117 & $\begin{array}{c}\text { Proposed } \\
(9-3) \\
\end{array}$ & 12.9:1 & 0.21 & 111 & $\begin{array}{l}\text { Miaou et.al. } \\
\quad(\varepsilon=5 \%)\end{array}$ & 14.1:1 & $5.99 *$ \\
\hline 117 & Lu. et. al. [33] & $10: 1$ & 2.96 & 111 & $\begin{array}{l}\text { Miaou et.al. } \\
\quad(\varepsilon=10 \%)\end{array}$ & $13.4: 1$ & $5.9 *$ \\
\hline 117 & Wel. el. al. [43] & $10: 1$ & 1.18 & 111 & $\begin{array}{c}\text { Proposed } \\
(\mathbf{1 5 - 3})\end{array}$ & 13.6:1 & $5.86^{*}$ \\
\hline 117 & $\begin{array}{c}\text { Bilgin et. al. } \\
\text { [44] }\end{array}$ & $10: 1$ & 1.03 & 118 & Gurkan & $6.0: 1$ & $0.98^{*}$ \\
\hline 117 & $\begin{array}{l}\text { Chou et. al. } \\
\text { app. } 2\end{array}$ & $10: 1$ & 0.98 & 118 & $\begin{array}{c}\text { Proposed } \\
(12-3) \\
\end{array}$ & 6.0:1 & $0.96 *$ \\
\hline 117 & $\begin{array}{l}\text { Filhoet. al. } \\
\text { app.3 }\end{array}$ & $10: 1$ & 0.86 & 119 & Bilgin et. al. & 21.6:1 & 3.76 \\
\hline 117 & $\begin{array}{l}\text { SangJoon Lee } \\
\text { et. al. }\end{array}$ & $10.4: 1$ & 0.42 & 119 & Tai et. al. [45] & $20: 1$ & 2.17 \\
\hline 117 & $\begin{array}{c}\text { Proposed } \\
(6-3)\end{array}$ & 9.9:1 & 0.14 & 119 & $\begin{array}{c}\text { Chou et. al. } \\
\text { app. } 2\end{array}$ & 20.9:1 & 1.81 \\
\hline 117 & Hilton [39] & $8: 1$ & $2.6^{*}$ & 119 & $\begin{array}{l}\text { Filho et. al. } \\
\text { app.3 }\end{array}$ & 20.9:1 & 1.92 \\
\hline 117 & Lu. et. al. & $8: 1$ & $1.18 *$ & 119 & $\begin{array}{l}\text { SangJoon Lee } \\
\text { et. al. }\end{array}$ & 19.3:1 & 2.05 \\
\hline 117 & Ku. et.al.[35] & $8: 1$ & $1.06^{*}$ & 119 & $\begin{array}{c}\text { Proposed } \\
(21-7)\end{array}$ & 19.8:1 & 0.89 \\
\hline 117 & $\begin{array}{c}\text { Proposed } \\
(4-2)\end{array}$ & 7.9:1 & $1.02 *$ & 119 & $\begin{array}{c}\text { Chou et. al. } \\
\text { app. } 2\end{array}$ & $10: 1$ & 1.03 \\
\hline 117 & $\begin{array}{c}\text { Hwang et.al. } \\
\text { [31] }\end{array}$ & $8: 1$ & $0.93 *$ & 119 & $\begin{array}{l}\text { Filhoet. al. } \\
\text { app. } 3\end{array}$ & $10: 1$ & 0.93 \\
\hline 117 & Lu et.al. & $8: 1$ & 1.18 & 119 & $\begin{array}{l}\text { SangJoon Lee } \\
\text { et. al. }\end{array}$ & $10.3: 1$ & 0.59 \\
\hline 117 & Bilgin et. al. & $8: 1$ & 0.86 & 119 & $\begin{array}{c}\text { Proposed } \\
(10-2)\end{array}$ & 10:1 & 0.23 \\
\hline 117 & $\begin{array}{l}\text { Filhoet. al. } \\
\text { app.3 }\end{array}$ & $8: 1$ & 0.75 & 119 & $\begin{array}{l}\text { Filhoet. al. } \\
\text { app.3 }\end{array}$ & $8: 1$ & 0.77 \\
\hline 117 & $\begin{array}{l}\text { SangJoon Lee } \\
\text { et. al. }\end{array}$ & $7: 1$ & 0.34 & 119 & $\begin{array}{l}\text { SangJoon Lee } \\
\text { et. al. }\end{array}$ & $8.5: 1$ & 0.44 \\
\hline 117 & $\begin{array}{c}\text { Proposed } \\
(4-2)\end{array}$ & 7.8:1 & 0.09 & 119 & $\begin{array}{c}\text { Proposed } \\
(6-2)\end{array}$ & 8.3:1 & 0.15 \\
\hline
\end{tabular}

${ }^{\mathrm{a}}$ : Test in a period of 5 minutes of the corresponding record

b: Test in a period of 10 minutes of the corresponding record

*: PRD of reconstructed samples with values ranging from -1024 to 1023 


\section{Conclusions}

Compressing ECG data is an effective solution to reduce the size transmitted of packages, which help avoid the congestions as well as decrease BER and the package loss rate. In this study, an extremely low-cost computational, general-purposed ECG compression algorithm, called the advanced twostate algorithm, was proposed, which could: (i) adapt various ECG conditions including both regular and irregular ECG, (ii) satisfy every size of the compressed package without affecting the quality of reconstruction, and (iii) is quite simple to implement in any kinds of network. This algorithm aims to separate the ECG signal into two parts: plain durations ( $\mathrm{P}$ and $\mathrm{T}$ wave), labelled as high-state durations and compressed at higher CR (hCR), and complex durations (QRS complex), labelled as low-state durations compressed at lower CR $(\boldsymbol{I C R})$.In the experiments

\section{References}

1. Mirza Mansoor Baig, Hamid Gholamhosseini. Smart health monitoring systems: an overview of design and modeling. J.Med. Syst. 37(2) (2013). doi: 10.1007/s10916-012-9898-z.

2. E.C. Kyriacou, C.S .Pattichis, M.S. Pattichis.An overview of recent health care support systems for eEmergency and mHealth applications. Conf. Proc. IEEE Eng. Med. Biol. Soc. 2009, 1246-1249. doi: 10.1109/IEMBS.2009.5333913.

3. J. Korhonen, Ye Wang.Effect of packet size on loss rate and delay in wireless links.Wireless Communications and Networking Conference, 2005 IEEE3, 16081613 (2005). doi: 10.1109/WCNC.2005.1424754.

4. N. Yaakob,I.Khalil, Hu Jiankun.Performance Analysis of Optimal Packet Size for Congestion Control in Wireless Sensor Networks.The 9th IEEE International Symposium on Network Computing and Applications (NCA), Cambridge, with all 48 records of MIT-BIH arrhythmia database and 9 records of $\mathrm{CU}$ ventricular tachyarrhythmia database, the performance result of the proposed algorithm were very promising at moderate CR. Almost the signals was reserved well at $\mathrm{CR}<15$. In the comparison with other loss-type methods even including some advanced methods like SPIHT or JPEG2000, the proposed method showed a superior result with lower PRD at the same CR despite of its simplicity in both compressing and decompressing process. Nevertheless, the proposed method cannot reach a higher CR without significantly damaging the signal like many other methods containing error minimization mechanism. In exchange, it can achieve many necessary requirements for a medical wireless network and, due to its dependence in physiological feature, the proposed algorithm can be used for other signals asides from ECG.

Massachusetts, 15-17 June 2010, 210-213. doi: 10.1109/NCA.2010.37.

5. Xuedong Liang, Ilangko Balasingham. Performance analysis of the IEEE 802.15.4 based ECG monitoring network. Proceedings of the Seventh IASTED international conferences: wireless and optical communications, Montreal, Quebec, Canada, 2007, 30 May - 1 June.

6. M.S. Manikandan', S. Dandapat. Wavelet threshold based TDL and TDR algorithms for real-time ECG signal compression. Biomedical Signal Processing and Control3(1), 44-66 (2008). doi: doi:10.1016/j.bspc.2007.09.003.

7. W. Mueller. Arrhythmia detection program for an ambulatoryECG monitor. Biomed. Sci. Instrum 14,81-85 (1978).

8. J.R Cox, FM Nolle, A. Fozzard, G. Oliver. AZTEC, a preprocessingprogram forrealtimeECGrhythmanalysis.IEEE.Trans.Biom ed.Eng.15(4), 128-129 (1968).

9. J.P. Abenstein, W.J. Tompkins. New data reduction algorithm for real-time ecg analysis. IEEE Trans Biomed Eng. 29(1), 43-48 (1982). 
10. M. Ishijima, S.B. Shin, G.H.Hostetter, J. S.klansky. Scan-along polygon approximation for data compression of electrocardiograms. Med Biol Eng Comput. 30(11), 723-729 (1983).

11. Y. Zigel, A. Cohen, A. Katz. ECG signal compression using analysis by synthesis coding, IEEE Trans. Biomed. Eng. 47(10), 308-316 (2000).

12. G. Nave, A. Cohen. ECG compression using long term prediction. IEEE Trans. Biomed. Eng. 40(9), 877-885 (1993). doi: 10.1109/10.245608.

13. P.S. Hamilton, W.J. Tompkins. Compression of ambulatory ECG by average beat subtraction and residual differencing. IEEE Trans. Biomed. Eng.38(3), 253-259 (1991). doi: $10.1109 / 10.133206$.

14. A. Cohen, Y. Zigel. Compression of multichannel ECG through multi-channel long-term prediction. IEEE Eng. Med. Biol. Mag. 16(4), 109-115 (1998). doi: 10.1109/51.646227.

15. A.Cohen,P.M.Poluta,R.ScottMillar.CompressionofECGsignalsusing vector quantization. Proceedings of the IEEE-90 S. A Symposium of the Communications and Signal Processing, COMSIG-90, Johannesburg, 1990, 45-54.

16. C.P. Mammen, B. Ramamurthi.Vector quantization for compressionof multichannel ECG. IEEE Trans. Biomed. Eng. $\quad 37(9), \quad 821-825$ (1990). doi: $10.1109 / 10.58592$.

17. S.G. Miaou, H.L. Yen.Multichannel ECG compression using multi-channel adaptive vector quantization. IEEE Trans. Biomed. Eng. 48(10), 1203-1207 (2001). doi: 10.1109/10.951524.

18. J. Cardenas-Barrera, J. Lorenzo-Ginori. Mean-shape vector quantization for ECG signal compression. IEEE Trans. Biomed. Eng. 46(1), 62-70 (1999). doi: 10.1109/10.736756.

19. W. Philips. ECG data compression with time-warped polynomials. IEEE Trans. Biomed. Eng. 40(11),1095-1101 (1993). doi:10.1109/10.245626.
20. L.V.Batista,E.U.K.Melcher,L.C.Carvalho. CompressionofECGsignals by optimized quantization of discrete cosine transform coefficients. Med. Eng.Phys.23(2), 127134 (2001). doi: 10.1016/S13504533(01)00030-3.

21. M.E. Womble, J.S. Halliday, S.K. Mitter, M.C. Lancaster, J.H. Triebwasser. Data compression for storing and transmitting ECGs/VCG's. Proceeding of IEEE65(5), 702-706 (1977). doi: 10.1109/PROC.1977.10550.

22. B.R.S. Reddy, I.S.N. Murthy. ECG data compression using Fourier descriptors. IEEE Trans. Biomed. Eng. 33(4), 428-434 (1986). doi:10.1109/TBME.1986.325799.

23. W.S. Kuklinski. Fast Walsh transform data-compression algorithm: ECG applications. Med. Biol. Eng. Comput. 21(4), 465-472 (1983). doi: 10.1007/BF02442635.

24. E. Berti, F. Chiaraluce, N.E. Evans, J.J. McKee. Reduction of Walsh-transformed electrocardiograms by double logarithmic coding. Trans. Biomed. Eng. 47(11), 1543-1547 (2000). doi: 10.1109/10.880108.

25. A.G. Ramakrishnan, S. Saha. ECG compression by multirate processing of beats. Comput. Biomed. Res. 29(5), 407409 (1996). doi: 10.1006/cbmr.1996.0030.

26. M. Blanco-Velasco.A low computational complexity algorithm forECG signal compression. Med. Eng. Phys. 26(7), 553568 (2004).

27. J.H. Husoy, T. Gjerde. Computationally efficient sub-band coding of ECG signals. Med. Eng. Phys. 18(2), 132-142 (1996). doi: 10.1016/1350-4533(95)00028-3.

28. R.S.H.Istepanian,A.A.Petrosian.Optimalzo nalwavelet-basedECGdata compression for a mobile telecardiology system. IEEE Trans. Inf. Tech- nol.Biomed.4(3), 200211 (2000). doi: 10.1109/4233.870030.

29. Sangjoon Lee, Jungkuk Kim, Jong-Ho Lee. A Real-Time ECG Data Compression and Transmission Algorithm for an e-Health Device. IEEE Trans. Biomed. Eng. 58(9), 2448-2455 (2011). doi: 10.1109/TBME.2011.2156794. 
30. R.S.H. Istepanian, L.J. Hadjileontiadis, S.M. Panas. ECG data compression using wavelets and higher order statistics methods. IEEE Trans. Inf. Technol.Biomed.5(2),108-115 (2001). doi: 10.1109/4233.924801.

31. W.J. Hwang, C.F. Chine, K.J. Li. Scalable medical data compression and transmission using wavelet transform for telemedicine applications.IEEE Trans. Inf. Technol. Biomed. 7(1), 54-63 (2003). doi: 10.1109/TITB.2003.808499.

32. S.G. Miaou, H.L. Yen.A quality-ondemand algorithm for wavelet-based compression of electrocardiogram signals. IEEE Trans. Biomed. Eng. 49(3), 233-239 (2002).

33. Z.Lu,D.Y.Kim,W.A.Pearlman.Waveletcom pressionofECGsignalsby the set partitioning in hierarchical trees method. IEEE Trans. Biomed. Eng.47(7),849-856 (2000).

34. B.S. Kim, S.K. Yoo, M.H. Lee. Waveletbased low-delay ECG compression algorithm for continuous ECG transmission. IEEE Trans. Inf. Tech- nol. Biomed. 10(1), 77-83 (2006). doi: 10.1109/TITB.2005.856854.

35. C.T. Ku, H.S. Wang, K.C. Hung, Y.S. Hung.A novel ECG data compressionmethodbasedonnonrecursivedi screteperiodizedwavelettransform.IEEE

Trans. Biomed. Eng. 53(12), 2577-2583 (2006) (Part1).

36. K. Nagarajan, E. Kresch, S.S. Rao, Y. Kresh. Constrained ECG compressionusingbestadaptedwaveletpack etbases.IEEESignalProcess.Lett.3(10), 273-275 (1996). doi: 10.1109/97.540070.

37. Hsieh-Wei Lee, King-Chu Hung, TsungChing $\mathrm{Wu}$, Cheng-Tung $\mathrm{Ku}$. A Modified Run-Length Coding towards the Realization of a RRO-NRDPWT-Based ECG Data Compression System.EURASIP Journal on Advances in Signal Processing 2011, 2011:703752. doi:10.1155/2011/703752.

38. Hakan Gurkan.Compression of ECG signals using variable-length classified vector sets and wavelet transforms.EURASIP Journal on Advances in Signal Processing 2012, 2012:119. doi:10.1186/1687-6180-2012-119.

39. M.L. Hilton.Wavelet and wavelet packet compression of electrocardiograms. IEEE Trans. Biomed. Eng. 44(5), 394-402 (1997). doi:10.1109/10.568915.

40. A. Alesanco, S. Olmos, R.S.H. Istepanian, J. Garcya. Enhanced real-time ECG coder for packetized telecardiology applications. IEEE Trans. Inf. Technol.Biomed.10(2),229-236 (2006). doi: 10.1109/TITB.2005.856853.

41. S.G. Miaou, H.L. Yen, C.L. Lin. Waveletbased ECG compression using dynamic vector quantization with tree codevectors in single codebook.IEEE Trans. Biomed. Eng. 49(7), 671-680 (2002). doi: 10.1109/TBME.2002.1010850.

42. S.G. Miaou, S.N. Chao. Wavelet-based Lossy-to-Lossless ECG compression in a unified vector quantization framework. IEEE Trans. Biomed. Eng.52(3),539-543 (2005). doi: 10.1109/TBME.2004.842791.

43. J.J. Wei, C.J. Chang, N.K. Chou, G.J. Jan. ECG data compression using truncated singular value decomposition. IEEE Trans. Biomed. Eng. 5(4), 290-295 (2001). doi: 10.1109/4233.966104.

44. A. Bilgin, M.W. Marcellin, M.I. Altbach. Compression of electrocardiogram signals using JPEG2000. IEEE Trans. Consum. Electron. 49(4), 833-840 (2003). doi:10.1109/TCE.2003.1261162.

45. S.C. Tai, C.C. Sun, W.C. Tan.2-D ECG compression method based on wavelettransformandmodifiedSPIHT.IEE ETrans.Biomed.Eng.52(6), 999-1008 (2005). doi: 10.1109/TBME.2005.846727.

46. H.H. Chou, Y.J. Chen, Y.C. Shiau, T.S. Kuo. An Effective and Efficient Compression Algorithm for ECG Signals With Irregular Periods. IEEE Trans. Biomed. Eng. 53(6), 1198-1205 (2006). doi: 10.1109/TBME.2005.863961.

47. H. Lee, K.M. Buckley. ECG data compression using cut and align beats approach and 2-D transforms. IEEE 
Trans. Biomed. Eng. 46(5) 556-565 (1999). doi: 10.1109/10.759056.

48. E.B.L. Filho, N.M.M.Rodrigues, E.A.B. da Silva, S.M.M. de Faria, V.M.M. da Silva, M.B.de Carvalho.ECG Signal Compression Based on Dc Equalization and Complexity Sorting. IEEE Trans. Biomed. Eng. 55(7), 1923-1926 (2008).

doi: 10.1109/TBME.2008.919880.
49. S.M.S. Jalaleddine, C.G. Hutchens, R.D. Strattan, W.A. Coberly.Ecg data compression techniques-a unified approach. IEEE Trans Biomed Eng. 37(4), 329-343 (1990). doi:10.1109/10.52340.

50. http://physionet.org/physiobank/database/mit $\mathrm{db} /$

51. http://physionet.org/physiobank/database/cud b/ 